Research Report

UKTRP-83-24

\title{
EVALUATION OF ASPHALTIC PAVEMENTS FOR OVERLAY DESIGN
}

by

Robert C. Deen

Director

Herbert F. Southgate

Chief Research Engineer

and

Gary W. Sharpe

Principal Research Engineer

Kentucky Transportation Research Program

University of Kentucky

Lexington, Kentucky

prepared for presentation to American Society for Testing and Materials symposium on

Pavement Maintenance and Rehabilitation

December 7, 1983

Bal Harbour, Florida 


\section{EVALUATION OF ASPHALTIC PAVEMENTS \\ FOR OVERLAY DESIGN}

INTRODUCTION

BASIS FOR THE EVALUATION METHODOLOGY

SIMULATION OF DYNAMIC DEFLECTIONS BY ELASTIC THEORY Loading

Input Parameters

Reference

THE DEFLECTION BOWL

EFFECT OF ERRORS AND MISSING DATA

EVALUATION PROCEDURES

AS-CONSTRUCTED THICKNESSES

ADJUSTMENTS FOR NONREFERENCE CONDITIONS

Moduli of Asphaltic Concrete

Adjustment Factors for Deflections

EVALUATION OF THE PAVEMENT STRUCTURE

Estimating Subgrade Strength

Interpretation of Defiection Data

Foundation or Subgrade Problems

Deficiencies in Bound Layers

Quantifying Effective Behavior

Estimation of Effective Structure

Fvaluation of Project Data

Sampling and statistics

DESIGN EOUIVALENT AXLELOADS

OVERLAY DESIGNS

CASE HISTORIES

I 65, MARSHALL COUNTY, TENNESSEE

EVALUATION OF PAVEMENT MILLING

MAGOFFIN COUNTY, KENTUCKY

STANDARDIZATION OF METHODOLOGY

OTHER APPLICATIONS

CONCLUSION

ACKNOWLEDGEMENTS

REFERENCES 


\section{ABSTRACT \\ EVALUATION OF ASPHALTIC PAVEMENTS \\ FOR OVERLAY DESIGN}

by

Robert C. Deen, Herbert F. Southgate, and Gary W. Sharpe Transportation Research Program

University of Kentucky

Lexington, Kentucky

KEYWORDS: Asphaltic Pavements, Overlay Designs,

Deflections, Deflection Bowl, Structural

Condition, Nondestructive Testing, Pavement

Evaluation, Subgrade Modulus, Asphaltic

Concrete Modulus, Equivalent Axleloads

To evaluate projects involving approximately 200 route-miles of interstate and primary pavements in Kentyexy and Tennessee in relatively short time frames, it was decided to test, analyze, and design overlays using test equipment (Road Rater) and procedures developed by the University of Kentucky Transportation Research Program. This paper presents the analysis methodology and the evaluation and overlay designs for selected projects, including the before-and-after analysis of milling on one project.

The Road Rater apolies a dynamic sinusoidal loading of known force and frequency. The velocity of the vibration waves are measured by sensors and integrated electronically to obtain surface deflections. An analysis of the shape and magnitude of the deflection bowl permits an assessment of whether the structure is performing as anticipated or whether some component is significantly weaker than designed. Analyses permit the determination of the "behavioral" or effective thicknesses of the asphaltic concrete layers and the in-place subgrade moduli. Strip charts of effective thickness and subgrade strength for alternatively, overlay thicknesses) along the length of a project permit delineation of the project into relatively uniform segments. The arithmetic mean and standard error are determined for each segment to estimate design parameters. The required overlay thickness is the difference between the total thickness required for new construction to carry the anticipated traffic and the behavioral thickness of the existing pavement. 


\section{INTRODUCTION}

Highway agencies for years have faced the problem of providing for the rehabilitation and rejuvenation of highway pavements. Typically, funds are insufficient to meet all such rehabilitation needs. In more recent years, the problem has been aggravated inasmuch as the great highway construction boom has now passed and all highway agencies, both state and local, are faced with a ballooned mileage of highways that must be maintained in a serviceable condition. Thus, the relative proportion of the rehabilitation budget

requirements to the total highway agency budget has

increased. A compounding factor is the general demand by
the public that governmental agencies manage public funds more effectively and efficiently. Additionally, public monies available for all purposes are generally decreasing (relatively), and therefore the demand for allocation among various governmental services is much sharper and more competitive.

The transportation infrastructure, in part consisting of the highway and street networks of this country; are a primary element in economic development and growth. With such large concentrations of population in relatively small areas, it is absolutely necessary that required and desired goods and services be delivered to those that are not able to completely service themselves (and in today's era of specialization, almost no one is completely selfsufficient). There is now a tremendous burden on highway agencies to protect the great financial investment 
represented by the highway and street systems. To make the most efficient use of available funds, it is necessary to select and schedule rehabilitation activities on a timely basis. If maintenance and rehabilitation are delayed, the level of service provided the traveling public decreases at an accelerating rate. Also, the cost of rehabilitation has been reported to be as much as four times that had the rehabilitation been performed at the proper time.

There are a number of tools and methodologies available to the highway engineer and administrator to assist in making decisions as to appropriate rehabilitation strategies. The most elemental and probably the first methodology to be used was to rely on visual surveys and observations of pavement conditions. Measurements of rutting and road roughness (ride quality) also have been used, along with measurements of the extent of cracking and patching, to provide input upon which to base decisions for rehabiliation activities. In more recent years, skid resistance of pavement surfaces has been involved in rehabilitation strategies. Unfortunately; these approaches of observing or measuring manifestations of pavement performance only from the surface are not always adequate. These traditional procedures may not show imminent, but hidden, structural deterioration.

Sometimes, to determine the actual structural capacity of a pavement system, it may be necessary to core the pavement. This, of course, is costly both in terms of funds and time and still may not provide the quantity of 
information necessary to evaluate the structural capacity of a network of highways or streets. In recent years, pavement deflections (more specifically, dynamic deflections) have been used as an additional input variable to the decision-making process of selecting and scheduling rehabilitation strategies. Dynamic deflections made by such apparatus as the Road Rater, Dynaflect, and the falling-weight deflectometer provide basic information related directly to the structural adequacy of the pavement system. This information, along with the other more conventional input factors of pavement condition and performance, permits a more complete analysis of the sufficiency of pavement systems on a project-by-project basis; resulting decisions relating to rehabilitation strategies are much more efficient.

The objective of this paper is to summarize and document a methodology that has been developed to evaluate the structural adequacy of asphaltic concrete pavements prior to preparing overlay designs and recommending other rehabilitation strategies. The methodology is based on elastic theory and a rational pavement thickness design schema. The procedure makes use of dynamic pavement deflections measured by the Road Rater. It also has been demonstrated that pavement deflections obtained with the Dynaflect are compatible with the procedure. The methodology is "dynamic" inasmuch as it is continually being refined, and the description of the methodology contained in this paper is as of the summer of 1983. Case histories also 
are presented to illustrate applications of the methodology to actual, "real-world" decisions related to overlay rehabilitation strategies.

\section{BASIS FOR THE EVALUATION METHODOLOGY}

\section{SIMULATION OF DYNAMIC DEFLECTIONS}

\section{BY ELASTIC THEORY}

Loading

The testing head of the Kentucky Road Rater consists of a vibrating mass of $72.6 \mathrm{~kg}\left(\begin{array}{lll}160 & \mathrm{lb}\end{array}\right)$ that impulses the pavement; the forced motion of the pavement is measured by velocity sensors located at $0,305,610$, and $914 \mathrm{~mm}(0,1$, 2, and $3 \mathrm{ft}$ ) from the center of the test head. Frequency of the vibrator may be chosen from $10,20,25,30$, or $40 \mathrm{~Hz}$. When the vibrating mass is lowered to the pavement under a hydraulic pressure of $4.82 \mathrm{MPa}(700 \mathrm{lbf} / \mathrm{sq}$ in.), the static load is $7.43 \mathrm{kN}(1,670 \mathrm{lbf})$.

At a frequency of $25 \mathrm{~Hz}$ and a double-amplitude of vibration of $1.52 \mathrm{~mm}(0.06 \mathrm{in.})$, the Road Rater has a double-amplitude dynamic force oscillation of $2.67 \mathrm{kN} \quad(600$ lbf). The composite loading consists of a static load of $7.43 \mathrm{kN}$ and a dynamic force amplitude of $1.33 \mathrm{kN}\left(\begin{array}{lll}300 & 1 \mathrm{bf}\end{array}\right)$ that oscillates about the static load.

The Road Rater loading is transmitted to the pavement by two feet symmetrically located on either side of a beam that extends ahead and supports the velocity sensors. For these symmetrical conditions, deflection calculations need be made only for one foot and the radii corresponding to 
each sensor location. Using superposition principles (1), deflections that result from the load applied to one foot must be added to deflections due to the load applied by the other foot to obtain the total deflection in the pavement at a given point.

The dynamic loading (sine wave) of the Road Rater may be approximated by a square wave such that the maximum value of the square wave is equal to $1 / \sqrt{2}$ times the peak value of the sine wave. The maximum and minimum square-wave loadings for the Kentucky Road Rater are 8.37 and $6.49 \mathrm{kN} \quad(1,882$ and 1,458 lof). From symmetry, the maximum and minimum loads on each foot of the test head are equal to 4.19 and $3.24 \mathrm{kN}$ (941 and 729 lbf), respectively. The total dynamic deflection is defined as twice the difference between the deflections calculated using the Chevron N-layered computer program (2) for the maximum and minimum loads. Input Parameters

Inputs required by the Chevron N-layered program include a contact pressure corresponding to the applied load; the number of layers; and the thickness; Young's modulus, and Poisson's ratio of each layer. The contact pressures of the maximum and minimum loads were selected to maintain the correct area for each loading foot. Values used in simulating the Road Rater loadings and deflections are summarized in Table 1.

The modulus of a granular base $\left(\mathrm{E}_{2}\right)$ is a function of the moduli of the confining layers, i.e., the modulus of the asphaltic concrete $\left(E_{2}\right)$ and the modulus of the subgrade 
$\left(E_{3}\right)$. Estimation of the modulus of the crushed-stone layer may be determined from the relationship $E_{2}=F \times E_{3}$, where there is an inverse linear relationship between $\log F$ and $10 \mathrm{~g} \mathrm{E}_{3}$. The ratio of $\mathrm{E}_{\boldsymbol{Z}}$ to $\mathrm{E}_{\mathbf{3}}$ is equal to 2.8 at a California bearing ratio (CBR) of 7 and to 1 when $E_{1}$ equals $\mathrm{E}_{3}$; i.e., $\mathrm{E}_{1}=\mathrm{E}_{2}=\mathrm{E}_{3}(3,4)$, the case of a Boussinesq semi-infinite half space. Laboratory triaxial testing also has indicated variations in modulus as a function of confining pressure. A modulus ratio of 2.8 (crushed-stone base to subgrade) at a CBR of 7 represents experience in Kentucky. The modulus of the-subgrate (in lbf/sq in.) can be approximated by the product of CBR and 1500 , a method of estimating moduli adequate for normal design considerations up to a CBR of about 17 to $20(3-7)$.

Reference Conditions.

The modulus of elasticity of asphaltic concrete varies as a function of frequency of loading and of temperature. Conditions for the current Kentucky thickness-design procedures and the method for conducting Benkelman beam (static) deflection tests correspond to a modulus of 3.31 GPa $(480,000 \quad \mathrm{lbf} / \mathrm{sq}$ in.) at $0.5 \mathrm{~Hz}$ and a pavement temperature of $21 \mathrm{C}(70 \mathrm{~F})$. A reference frequency of $25 \mathrm{~Hz}$ was selected for the Road Rater; the corresponding modulus of asphaltic concrete at $21 \mathrm{C}$ is $8.27 \mathrm{GPa}(1,200,000 \mathrm{lbf} / \mathrm{sq}$ in.), obtained using Figure 1. The equation presented in Figure 1 is a close approximation of results of laboratory testing by Shook and Kallas (8) . 


\section{THE DEFLECTION BOWL}

Analyses of pavement deflections involve examinations of the shapes of deflection bowls $(6,7,9-17)$. The shapes of typical deflection bowls are illustrated in Figure 2. An empirical evaluation of the shape of a deflection bowl involves extrapolating a straight line through the Road Rater deflections of the No. 2 and No. 3 Sensors when log deflection is plotted as a function of the arithmetic distance from the load head. The deflection at the position corresponding to the No. 1 Sensor is the No. 1 projected deflection (1P in Figure 3, for example). The slope of the

semi-log secant line, the difference between the No. 1
projected (IP) and the No. 1 Sensor (IM) deflections, and the magnitude of all deflections are all indicative of the shape of the deflection bowl.

Typically, there is a difference between the No. 1 projected and the No. 1 Sensor deflections, both for theoretical deflections (calculated using the Chevron $\mathrm{N}$-layered program and design or as-constructed input parameters) and for field-measured deflections. Normally; differences between the No. 1 projected deflection and the No. 1 Sensor deflection for both theory and field measurements are the same (see Figure 3). However, when these differences are not the same, unanticipated behavior of the pavement system is indicated. For example, slab deterioration is suggested when field measurements indicate a No. 1 Sensor deflection greater that the No. 1 projected deflection and the difference between these values is 
greater than the difference for theoretical deflections (see Figure 3). On the other hand, a foundation problem, or lack of supporting capability, may be indicated by increased magnitudes of all field deflections and a No. 1 projected deflection greater than the No. 1 Sensor deflection (see Figure 3). Also, the difference between the No. 1 projected deflection and the measured No. 1 deflection should be greater than the difference for theoretical deflections.

A log-log plot of No. 1 projected deflections versus No. 1 Sensor deflections may be used to identify variations in behavior of the pavement structure. The solid line in Figure 4 shows the theoretical relationship for a given structure and asphaltic concrete modulus. Subgrade modulus increases logarithmically (approximately) along the line as deflections decrease. The approximate logarithmic scale is a function of pavement structure. The two dashed lines indicate the variation in position of the theoretical line due to changes in magnitudes of the deflections by tone unit $\left(2.54 \times 10^{-4} \mathrm{~mm}\right.$ or $\left.1 \times 10^{-5} \mathrm{in.}\right)$ on the Road Rater meters and the associated shift in calculated No. 1 projected deflections. The zone inside these dashed lines represents an expected variation due to reading the meters of the Road Rater.

\section{EFFECT OF ERRORS AND MISSING DATA}

Current procedures utilize deflections of the three sensors nearest the point of load application to evaluate the shape of the deflection bowl. Comparisons between the 
shape of the measured deflection bowl and the theoretical bowl provide estimates of effective thicknesses and subgrade moduli. Since analysis of Road Rater data involves all deflections simultaneously, it is important to understand the effects of errors for any or all measurements.

Normal operating tolerance for reading the Road Rater meters is tone unit. The probability of the occurrence of an error of plus one unit or of minus one unit for any given sensor is $1 / 3(33.3$ percent $)$. However, the probability of the occurrence of an error in one sensor reading for a single set of readings (deflection-bowl) is reduced to $1 / 9$ (11.1 percent) (nine possible combinations of a unit variation in reading a single scale or meter). The probability of the occurrence of an error of plus one unit or of minus one unit on two of the three Road Rater sensors for a single deflection bowl is $1 / 18$ ( 5.6 percent). The probability of the simultaneous occurrence of a similar error in all three sensor readings is even more remote (1/27 or 3.7 percent).

There are numerous combinations of errors of plus or minus one unit. Analyses have indicated that an error for the No. 2 Sensor is most critical for current analysis procedures. It also has been determined that errors of plus or minus one unit for the No. 2 sensor in combination with and minus or plus one unit for the No. 3 Sensor are most critical when two errors occur simultaneously. The most critical simultaneous errors in all three sensor readings are minus or plus one unit for the No. 1 sensor, plus or 
minus one unit for the No. 2 Sensor, and minus or plus one unit for the No. 3 Sensor.

These errors in reading Road Rater meters affect predictions of the behavior of existing pavements. The extent of the effect is a function of the thickness and strength of each layer and the strength of the subgrade. Normal operator error affects more significantly the results of analyses when the magnitudes of deflections are small, because a unit change produces a greater change in predicted subgrade strength and(or) effective pavement thickness (see dashed Iines in Figure 4 i.

Occasionally, situations arise such that data for one of the sensors may be missing or obviously erroneous. In that event, data may be analyzed using procedures published previously (7). The short-cut procedure reported in this paper is not applicable since that approach is predicated upon an analysis of both the shape and magnitude of the deflection bowl.

Table 2 illustrates a portion of deflection data where the the third sensor occasionally short circuited because of

a broken wire in the cable connection. That condition was recognized and corrected, but not before a significant segment of the project had been tested. Information presented on the left portions of Table 2 are representative of typical output from a computerized analysis of Road Rater deflections utilizing the short-cut procedure. Note particularly the column labeled "ASPH T-EFF" and the very low magnitude of the effective thicknesses of asphaltic 
concrete. An inspection of the unadjusted field deflection readings "SEN 1 RDG," "SEN 2 RDG," and "SEN 3 RDG" indicated the values for the third sensor were abnormally low for the specific pavement section being tested.

Since the short-cut analysis was not applicable, it was necessary to use deflections at the first and second sensors to estimate the subgrade modulus. A mean subgrade modulus may then be calculated and plotted as a function of the deflection at Sensor No. 1. Interpolation may be used to estimate the effective thickness of asphaltic concrete using the short-cut methodology. Results of those analyses are presented in the two columns to the far right of Table 2 . Those results are more reasonable than for the short-cut analysis.

\section{EVALUATION PROCEDURES}

\section{AS-CONSTRUCTED THICKNESSES}

To properly evaluate the behavior of asphaltic concrete pavements, thicknesses of the component layers must be determined from the most reliable construction or maintenance records or by coring the pavement, if adequate records are not available. Analysis procedures are predicated on matching measured deflections with some theoretical deflection bowl. There are many combinations of layer thicknesses, layer moduli, and subgrade moduli that may result in a deflection bowl that matches field measurements. It is readily apparent that only a few of those combinations represent realistic configurations. 
Initial procedures were of an iterative nature. More recently, procedures have been streamlined to eliminate the need for iterations. However, the existing layer thicknesses are necessary as a starting point for the analysis and also to assess whether results are realistic.

Specific portions of the analysis affected by the initial layer thicknesses include the following:

1. Estimation of the temperature distribution within the asphaltic concrete and the resulting mean pavement temperature (affects the magnitudes of the deflection adjutment factors and the average modulus of elasticity of the asphaltic concrete).

2. Estimation of the in-place subgrade modulus, and

3. Estimation of the appropriate worth (structural capacity) of the existing asphaltic concrete.

If the estimated as-constructed thicknesses are too thin, a hot summer day will result in a temperature distribution too high, an adjustment factor too large, an estimated subgrade modulus that is too high, and an equivalent thickness of asphaltic concrete too large. Conversely; assuming the as-constructed thickness of the asphaltic concrete greater than actual, the temperature distribution will result in a lower average temperature than expected, a lesser deflection adjustment factor, too weak a subgrade modulus, and too small an effective thickness of the asphaltic concrete. Fortunately, a given error in the assumed value of the as-constructed thickness of the crushed-stone base affects the estimate of the in-place subgrade modulus and behavioral 
thickness of the asphaltic concrete much less than the same error in the as-constructed thickness of the asphaltic concrete.

\section{ADJUSTMENTS FOR NONREFERENCE CONDITIONS}

Moduli of Asphaltic Concrete

Field measurements include Road Rater deflections, surface temperatures, time of day, and frequency of vibration. The surface temperature, time of day, and mean air-temperature history for the previous five days are necessary to determine the temperature distributions within the pavement structure using a method developed by southgate and Deen (18, 19). The five-day mean air-temperature history can be obtained from weather records at local offices of the National Oceanic and Atmospheric Administration or local radio and $\mathrm{TV}$ stations.

The mean modulus of elasticity of asphaltic concrete is a function of frequency of loading and mean pavement temperature $(8,20)$. A relationship between modulus and temperature may be developed for the reference frequency of $25 \mathrm{~Hz}$, or any other frequency that may be representative of other dynamic loads (Figure 1). Thus, a distribution of the modulus through the asphaltic concrete layer for the reference frequency of $25 \mathrm{~Hz}$ may be determined for any temperature distribution. For layers thinner than $152 \mathrm{~mm}$ (6 in.), results were better when the pavement modulus was taken as the average of the moduli on $12.7-\mathrm{mm}$ (0.5-in.) intervals beginning at the 25.4-mm (1-in.) level. For 
thicknesses greater than $152 \mathrm{~mm}$, the most representative modulus appreared to be the mean of moduli on $25.4-\mathrm{mm}$ intervals beginning at the 25.4-mm level. For pavements thicker than about $125 \mathrm{~mm}$ (5 in.), a mean of moduli at the top, middle, and bottom of the layer also was representative.

Adjustment Factors for Deflections

Because of the significant effect of temperature on the modulus of elasticity of asphaltic concrete, it is necessary to adjust deflection measurements to a reference temperature and modulus. One method of developing adjustment faeters is to use ratios of deflections for variations in modulus and thickness of the asphaltic concrete layer and subgrade modulus. Such ratios can be used to adjust deflections to a reference condition. In Figure 1 , the moduli at $21 \mathrm{C}$ (selected as the reference in Kentucky) are $3.31 \mathrm{GPa}$ for 0.5 $\mathrm{Hz}$ (Benkelman beam loading rate) and $8.27 \mathrm{GPa}$ for $25 \mathrm{~Hz}$ (Road Rater loading rate). For a given thickness of asphaltic concrete, adjustment factors vary according to changes in the thicknesses of granular base and the values of $E_{3}$, but these variations are minimal when compared with variations in adjustment factors for differences in thicknesses of asphaltic concrete layers. Thus, adjustment factors for all crushed-stone base thicknesses for a constant subgrade modulus and thickness of asphaltic concrete were averaged into a single line. Treating other thicknesses in the same manner produces similar relationships. Investigation of other subgrade moduli 
indicated only minor variations in adjustment-factor values for the same thickness of asphaltic concrete. The adjustment-factor curves shown in Figure 5a were produced by averaging the adjustment factors for each thickness of asphaltic concrete and across subgrade moduli.

Two-layered pavements show similar variations in adjustment factors relative to $\mathrm{E}_{3}{ }^{\prime} \mathbf{s}$ and asphaltic concrete thicknesses. The adjustment-factor curves shown in Figure 5b were produced by averaging adjustment factors for all $\mathrm{E}_{3}{ }^{\prime} \mathbf{s}$ and a constant thickness of asphaltic concrete. A mean pavement modulus can be found using the distribution of asphaltic concrete moduli through the pavement. The necessary adjustment factor (a multjplier) required to bring the field deflection to a deflection at a reference modulus is determined using the appropriate adjustment-factor chart (see Figure 5) and the mean modulus of elasticity of the asphaltic concrete layer.

An alternative method of presenting the adjustment factors is shown in Figure 6. The system shown adjusts the deflections to specific conditions -- $25 \mathrm{~Hz}$; a mean pavement temperature of $21 \mathrm{C}$, and $\mathrm{E}_{\mathfrak{l}}$ of $8.27 \mathrm{GPa}$. Figure 5 was developed on a basis of mean modulus of the asphaltic concrete layer. Figure 6 was developed from Figures 5a and $5 \mathrm{~b}$ for more convenient direct adjustments on the basis of mean pavement temperatures. Factors from Figure 5 adjust Road Rater deflections to a reference modulus $\mathrm{E}_{1}$ of $8.27 \mathrm{GPa}$ regardless of the frequency of loading. Factors from Figure 
6 adjust Road Rater deflections to a reference temperature, frequency, and modulus ( $21 \mathrm{C}, 25 \mathrm{~Hz}$, and $\mathrm{E}_{1}$ of $8.27 \mathrm{GPa}$ ).

The adjustment-factor schema presented in Figures 5 and 6 was developed using theoretical deflection data corresponding to the No. 1 Sensor of the Road Rater. A similar system also was developed for deflection data for both the No. 2 and No. 3 Sensors. A comparison of the three different adjustment factors indicated an average difference of \pm 0.032 between Sensors No. 1 and No. 2 and an average difference of \pm 0.048 between Sensors No. 1 and No. 3 for a range of asphaltic concrete moduli of 1.38 to $13.8 \mathrm{GPa}$ $(200,000$ to $2,000,000 \mathrm{lbf} / \mathrm{sq}$ in.). The greater differences in adjustment factors occurred at lower values of moduli and for thinner layers of asphaltic concrete. Initially, deflection adjustment-factor curves shown in Figures 5 and 6 were assumed to be adequate for any of the sensors (No. 1 , No. 2, or No. 3) of the Kentucky Road Rater. However, experience has shown that use of a single adjustment factor for all sensors may lead to a skewed deflection bowl that may result in erroneous evaluations. Thus, separate adjustment factors now are used for each sensor. An equation representing the relationships in Figure 5 has been developed to calculate adjustment factors. The equation and coefficients for all sensors are presented in Table 3 (21).

\section{EVALUATION OF THE PAVEMENT STRUCTURE}

Foundation (subgrade) stiffness (or modulus of elasticity) is a factor affecting the behavior of a pavement 
structure. Thus, estimates of subgrade strength are necessary to evaluate overall pavement conditions. A "design" condition exists when there is no loss of "effective" thickness in any of the layers. Deterioration or deficiencies in the layers of the structure means that performance is similar to another combination of layer thicknesses composed of reference-quality materials. In such cases, it is necessary to estimate the "effective" thicknesses of the deteriorated layers of the pavement structure. This may be accomplished by determining a realistic combination of layer thicknesses at reference conditions and subgrade modulus that results in a theoretical deflection bowl matching the measured deflection bowl.

Estimating Subgrade Strength

For given layer thicknesses, relationships were developed (from elastic theory) between theoretical deflections and subgrade moduli for a constant (reference) asphaltic concrete modulus of elasticity (Figure 7 and Table 4). The methodology for utilizing these relationships to estimate subgrade strength has evolved through several stages. Initially, the first three sensor deflections were used to obtain three estimates of the subgrade modulus, which then were averaged. The methodology was simplified so only the No. 2 Sensor deflection was used $(4,7)$. Further refinements utilized the No. 2 and No. 3 deflections to compute a No. 1 projected deflection. The measured No. 1 Sensor deflection and the No. 1 projected deflection are 
then plotted and compared to values predicted by elastic theory.

Subgrade moduli may be estimated using deflections, measured by any of the sensors singly or in combination. Moduli may vary slightly, but those variations usually are not significant.

Interpretation of Deflection Data

Foundation or Subgrade Problems -- When a foundation problem exists, the deflection bowl is much "broader" and "flatter" than would be expected, and the magnitudes of all measured deflections are greater than those predicted by elastic theory for the anticipated design conditions (Figure 2). In areas suspected of deficiencies in the subgrade and supporting (unbound) layers, tests indicated there was more variability among the deflections for No. 2 and No. 3 Sensors than among the measured deflections for the No. 1 Sensor. In such situations, either the No. 2 or No. 3 Sensor deflections, or both, and the associated No. 1 projected deflections are not matching elastic theory.

Deficiencies in Bound Layers $=$ Conversely; if there is a deficiency in the bound layer (asphaltic concrete), the deflection bowl bends sharply about the point of application of the load (Figure 2). The measured deflection at Sensor No. 1 is considerably greater than its theoretical counterpart while the No. 2 and No. 3 deflections very closely match predictions from elastic theory. Deflection bowls of this shape are usually observed where there are signs of pavement distress such as cracking and rutting. 
Quantifying Effective Behavior -- Measured Road Rater deflection bowls can be evaluated by comparing to theoretically expected relationships. Pavement behavior (or condition) can be given in terms of a predicted subgrade modulus, effective layer thicknesses, and effective moduli of the layers. The effective behavior may be expressed by any combination of these variables that matches the measured deflection bowl. In methodologies presented in this paper, pavement behavior is expressed in terms of a predicted subgrade modulus and an effective thickness of "reference" high-quality asphaltie concrete. The-effective thiekness of the granular base is assumed to be equal to the as-constructed thickness.

Determining a "true" and reasonable effective structure of an existing pavement is an iterative process. The reasonableness of the combinations of subgrade strengths and effective thicknesses of the asphaltic concrete is dependent upon the physical constraints (measured deflections and as-constructed thicknesses) of a given pavement structure. The iterative process involves selecting a subgrade modulus and effective thickness and comparing the resulting theoretical deflection bowl to the measured bowl. If the deflection bowls do not match, the subgrade modulus and effective thicknesses are adjusted and the process repeated until a satisfactory match is obtained.

Figure 8 (a combination of Fiqures 4 and 7) illustrates a "short-cut" procedure that usually eliminates the need for iterations. The methodology utilizes the theoretical 
relationship between No. 1 projected deflections and No. 1 Sensor deflections and the theoretical relationship between subgrade moduli of elasticity and No. 1 Sensor deflections.

Elastic theory has been used to simulate the relationship of surface deflection at the position of the No. 1 Sensor as a function of subgrade modulus, thickness of a crushed-stone base, and thickness of asphaltic concrete. The constructed thickness of asphaltic concrete will result in a relationship having the lowest deflection for a given subgrade modulus. Theoretically, as the pavement becomes thinner, the deflection will increase. Thus, a family of lines can be constructed to relate theoretical deflection of. the No. 1 Sensor, subgrade modulus, and thickness of asphaltic concrete as shown on the right side of Figure 8 . Table 4 summarizes the equations and coefficients of the family of curves.

Deflections for the second and third sensors are used to calculate a projected deflection for the position of the No. 1 Sensor (see section entitled THE DEFLECTION BOWL). A theoretical relationship between No. 1 Sensor deflections and projected deflections for constructed thicknesses of asphaltic concrete at reference conditions is illustrated by the solid line on the left portion of Figure 8 (also see Figure 4). Deflections measured by the second and third sensors are more indicative of the condition of the subgrade. Deflections of the No. 1 Sensor are indicative of the condition of the asphaltic concrete layer. 
For the " $\mathrm{x}$ " point in Figure 8, deflections for the second and third sensors produced a calculated projected deflection too small when compared to the companion measured deflection for the No. 1 Sensor. This "abnormal" condition indicates the asphaltic concrete is performing as a thinner layer. If the measured deflection for the No. 1 Sensor is used to estimate the subgrade modulus, the effective behavior is as if the full thickness of the asphaltic concrete were on a weaker subgrade. In that case, the measured deflections for the second and third sensors would not match the theoretical deflections. Therefore, it is necessary to "correct" the "measured" projected deflection to be compatible with deflections at the second and third sensors on the basis of the theoretical relationship between projected deflections and No. 1 Sensor deflections (left side of Figure 8). However, the deflection of the first sensor indicates the thickness of the asphaltic concrete is thinner than the actual thickness. To duplicate the measured deflection bowl, the equivalent structure that matches the condition is one of a thinner asphaltic concrete layer on a stronger subgrade. To obtain that structure having an equivalent behavior, the theoretical deflection is determined by moving vertically from the calculated projected deflection to the solid line on the left side of Figure 8 (Step 1). Using that point as a turn, move horizontally (Step 2) to obtain the estimated in-place subgrade modulus from the theoretical relationship between deflection and subgrade modulus for the constructed 
thickness of asphaltic concrete (heavy line on the right side of Figure 8 ). Using that estimated subgrade modulus as a turning point, move vertically (Step 3 ) to the measured deflection (Step 4) for the No. 1 sensor to obtain the estimated thickness of the asphaltic concrete (from the lighter solid lines on the right side of Figure 8 ).

The other most commonly measured deflection bowl is illustrated by the "o" point in Figure 8. There the deflection bowl is very flat, normally indicating a weak subgrade condition. When deflection bowls of this sort are encountered, the magnitudes of the deflections at the second and third sensors are much larger than theoretically expected and are not compatible with the measured No. 1 deflection. Therefore, it is again necessary to "correct" the measured deflection at the first sensor to be compatible with companion measurements for Sensors No. 2 and No. 3. Since the measured deflections at the second and third sensors are indicating a weakened subgrade, the unadjusted measurements are first used to estimate an in-place subgrade strength by moving horizontally along the value of the measured deflection of the No. 1 Sensor to the heavy solid line on the right side of Figure 8 (Step 5). The adjusted deflection for the first sensor (found by moving vertically from the measured deflection to the solid line on the left side of Figure 8 (Step 6) to locate another turning point) is used to estimate an effective thickness of asphaltic concrete (Steps 7 and 8). Comparisons with earlier analyses (5, 15) indicate that this procedure will normally result in 
a slightly stronger subgrade modulus coupled with a reduced asphaltic concrete thickness that produces a theoretical deflection bowl matching the measured bowl.

Analyses of field deflections indicated this procedure will produce results that can be used as input into an overlay design process without iteration. Road Rater testing of pavements before and after overlaying shows the ultimate behavior of the overlaid pavement is equal to that of a pavement having a total thickness of reference-quality asphaltic concrete equal to the sum of the effective thickness before overlaying and the overlay thiekness $(4$, 7).

Estimation of Effective Structure

The determination of the effective pavement structure is illustrated by the right side of Figure 8 . If the pavement is performing as one having a thickness equal to or greater than the design thickness of asphaltic concrete, the field data will plot on the theoretical line. If the field data plot above the line, the pavement is performing as one made of the reference materials but that is thinner than the

design and(or) constructed thickness.

When pavement performance is expressed in terms of reduced layer thicknesses, all layers may be varied in any combination of thickness of reference materials and a predicted subgrade modulus that result in a deflection bowl matching the measured bowl. The present procedure, however, maintains a constant crushed-stone thickness (equal to the as-constructed thickness) and expresses pavement behavior as 
a reduced thickness of asphaltic concrete at the reference modulus. If this method is used, lines of reduced thickness of asphaltic concrete can be superimposed onto the plot of No. 1 Sensor deflection versus subgrade modulus. The effective thickness may be interpolated from those lines (right side of Figure 8 ).

Evaluation of Project Data

Figure 9 illustrates the variation in predicted subgrade moduli from April to september based on data obtained in Kentucky over a one-year period. Such analyses permit the adjustment of deflection data obtained at any time to equivalent springtime deflections, when the subgrade is typically in the weakest condition. Analyses of Kentucky data indicated that fall tests provide the most consistent long-term indicator of pavement behavior. However, overlay designs are based on the subgrade in its weakest condition. Thus, Figure 9 permits an approximate adjustment of test data to springtime conditions. Tests performed on interstate pavements in Tennessee from August through March confirmed the pattern of Figure 9. The minimum spring value for Tennessee was approximately 0.55 compared to 0.60 for Kentucky •

One method for evaluating the performance of existing pavement structures has been to create a strip chart of in-place subgrade modulus (estimated from the analysis of deflection data) versus distance along the proposed project (Figure 10). Subgrade modulus (psi) may be converted to CBR by dividing by 1500. Two advantages are apparent. First, 
those locations exhibiting unusually weak subgrades are easily identified. Special spot overlay designs may be recommended for those locations to make more uniform the support of the general overlay. Second, the minimum subgrade modulus and the locations of significant changes in subgrade support are easy to detect. "Uniform" sections of highway may be delineated for possible consideration for various overlay designs. Similarly, strip charts of the effective thickness of the asphaltic concrete layer may be prepared (Figure 11). Again, locations of excessively thin effective thieknesses and-changes in the magnitude of effective thickness can be-delineated.

Sampling and Statistics

The sampling interval for deflection testing varies according to specific analysis requirements. For example, the density of testing can be low when the objective is to estimate effective pavement behavior for long lengths of highway. The current density of testing for analysis of asphaltic concrete pavements for overlay design purposes is at $0.16-\mathrm{km}(0.1-\mathrm{mile})$ intervals for each direction or lane tested. Generally, overlay thicknesses are not varied in short lengths, and therefore, low-density testing is acceptable. If a specific problem area is to be evaluated, higher densities of testing may be required to delineate the limits of the problem area. In such cases, testing has been done on $30-m(100-f t)$, or less, intervals.

Statistical analyses of the results of the evaluation of deflection data (i.e., expressions of in-place behavior 
such as effective pavement thickness or subgrade strengthl are normally oriented toward the selection of design values. It is desirable to select some level of pavement performance (required overlay thickness) that represents a tolerable balance between some overdesign and some acceptable risk of premature failure. For example, use of mean values for design purposes recognizes a 50-percent probability of premature failure. The design curves (Figure 12.) used in Kentucky are based on the 90-percentile level (i.e., there is assumed to be only a 10-percent probability of premature failure). The statistical levels assigned to other aspects of the evaluation of the structural adequacy of pavements (effective thicknesses and in-place subgrade muduli) can be varied, depending upon the type of facility under consideration, the funds available for rehabilitation, and the degree of risk acceptable to the highway design engineer and administrator.

The larger the sample size, the greater the reliability that may be attributed to the data analysis. A sample size of 30 or more measurements (of deflection bowls) is generally required for most statistics to be considered acceptable, although there are no firm rules regarding sample size. However, the assumption of a normal distribution is more valid with larger sample sizes.

\section{DESIGN EQUIVALENT AXLELOADS}

.To prepare an overlay design, it is necessary to estimate or predict the characteristics of the anticipated 
traffic stream that is to be served by the section of highway under consideration. To use Kentucky's current thickness design procedures, the characteristics of the traffic stream must be expressed in terms of equivalent 80-kN (18-kip) axleloads (EAL's) anticipated during the design . period. Several procedures are available to obtain such estimates $(3,4,22)$.

\section{OVERLAY DESIGNS}

On a strip chart similar to Figure 10, delineate lengths of the project that can be considered to have "uniform" (more or less) conditions of in-place subgrade strengths, effective thicknesses, and design EAL's. After selecting the acceptable design risks (as discussed above), determine the design subgrade strengths and effective thicknesses for each of the design sections.

Once the input parameters (in-place subgrade moduli, effective thicknesses of asphaltic concrete, and design EAL's) have been determined by analyses of deflection and traffic data; overlay designs can be prepared. First, from Figure 12, determine the total structural thicknesses for at least three designs using the existing thickness of the crushed-stone base. Plot and connect those points to obtain Curve $A$ in Figure 13. For the design EAL and in-place subgrade modulus, determine three total design thicknesses from Figure 12. Plot those designs on Figure 13 and connect to obtain Curve B. The intersection of Curves A and $B$ is the required total thickness for the design conditions. 
Overlay requirements can be determined as the difference between the total thickness required for "new" construction (the intersection of Curves $A$ and $B$ ) and the effective thickness of the existing pavement in the design length.

An inspection of strip charts similar to Figures 10 and 11 may reveal data points that apparently represent extremely weak pavement conditions (over short lengths) when compared to the majority of the data for the design section. In selecting the design in-place subgrade strengths and effective thicknesses (by applying acceptable levels of risiss), those "weak" points may be removed from the analysis of statistical parameters. Special structural patches, to be placed before overlaying, may be designed for those weak locations to return them at least to the design conditions for that section.

An alternative approach is to prepare an overlay design for each test point using the in-place subgrade and effective thickness for that point. These overlay designs then may be plotted on a strip chart and design sections delineated and statistical parameters applied to select the overlay design for each section.

The test point-by-test point preparation of overlay designs apparently results in thinner overlay thicknesses than using the worst expected design parameters determined separately from strip charts of in-place subgrade and effective thickness. Even though experience has indicated acceptable behavior can be anticipated when using the more conventional designs, some have expressed concerns that 
those designs are too conservative. The alternative point-by-point approach may be a viable compromise. Unfortunately, there is very little documented experience relative to specific design confidence levels from field performance histories. These issues currently are being studied.

\section{CASE HISTORIES}

\section{65, MARSHALL COUNTY, TENNESSEE}

At the request of the Tennessee Department of Transportation, the Kentucky Road Rater and analysis procedures were used to evaluate the existing condition of a portion of I 65 in Marshall County. That analysis was accomplished prior to the preparation of overlay designs for the project. Estimates of in-place subgrade strengths and effective thicknesses were used to design overlays. Traffic data were provided by Tennessee officials. A sampling of the data-collection process and the results of the pavement evaluation are illustrated in Figures 14 through 19.

EVALUATION OF PAVEMENT MILLING

Deflection testing performed in August 1982 indicated a deteriorated condition in the asphaltic concrete layers on I 65 from MP 22.6 to 27.2 in Marshall County, Tennessee (a portion of the above project). It was decided to mill the top portion (76 mm ( $3 \mathrm{in.}$ ) of original construction and 25 $\mathrm{mm}$ (.1 in.) of maintenance overlay) so that $235 \mathrm{~mm}(9.3 \mathrm{in.})$ of asphaltic concrete remained. Questions were raised 
concerning the structural worth of the material to be removed.

To assess the structural capacity of the milled material, Road Rater evaluations were conducted before and after milling. Deflection measurements were obtained during April and May 1983. Considering the difficulty of testing the exact locations before and after milling, mean values were used for comparisons, rather than test point-by-test point comparisons. Table 5 summarizes results for each of three test lengths.

The difference between the effective behavioral thickness before milling and after milling was approximately $50 \mathrm{~mm}$ (2 in.), with slight variations depending on the particular test area. Thus, it was hypothesized that the milled material was worth structurally only 50 percent of the actual thickness removed by milling. It also was noted that the standard error was less after milling than before.

\section{MAGOFFIN COUNTY, KENTUCKY}

The Kentucky Transportation Research Program has been conducting an extensive deflection survey and analysis program for the Kentucky Department of Highways for the past two years to provide input into annual rehabilitation programs. Pavement roughness surveys and visual inspections are used to select sites for deflection testing. A recent example included in those activities was a section of KY 114 in Mogoffin County. The segment of highway in question was constructed as $150 \mathrm{~mm}$ (6 in.) of asphaltic concrete on 300 
mm (12 in.) of dense-graded aggregate base. The pavement is subject to considerable heavy coal-hauling traffic.

Road Rater deflection measurements were obtained at $0.16-\mathrm{km}$ (0.1-mile) intervals during June 1983. Results of the analyses are presented in the left portions of Table 6 . Overlay designs were determined in two separate analyses for comparison purposes. Two columns of Table 6 present the springtime $C B R^{\prime} s$ and the required overlay thicknesses when the data were evaluated on a test point-by-test point basis. The spring CBR was computed by dividing the estimated subgrade modulus by 1500 and then multiplying by a factor (from Figure 9) dependent upon date of testing to adjust to springtime conditions. The column labeled "IOL" is the required overlay thickness for each test point. Statistical analyses may be applied to the individual overlay thicknesses to select an appropriate overlay design. Strip charts also may be prepared to determine locations where changes in overlay designs may be required or desirable.

The column of Table 6 labeled "WSPR CBR" illustrate the design springtime $C B R$ for a length of pavement as determined from a strip chart of subgrade modulus. The column labeled "OL" is the recommended overlay thickness for that length of pavement. Statistical analyses were used to select an 80th-percentile effective thickness of asphaltic concrete, which was combined with the design springtime CBR (also 80th percentile) to compute the required overlay thickness. An 
eight-year design EAL of $1.33 \times 10^{6}$ was used in the analyses.

From the column labeled "OL-IOL," it is noted that the point-by-point analysis resulted in somewhat thinner overlay thicknesses. Extremely weak conditions are indicated in those areas where the overlay thickness by the point-bypoint analysis (IOL) were greater than by the section analysis (OL). If desired, structural patches may be designed and constructed to bring those isolated weak areas up to the design level for the section.

\section{STANDARDIZATION OF METHODOLOGY}

Existing methodologies for structural evaluations of pavements are very much individualized to a specific organization's or agency's needs. As a result, there is no "standard method." Standardization should consider a number of issues, including but not necessarily limited to the following:

A. calibration and correlation of equipment,

B. sampling strategies; and

C. analysis methodologies:

1. correlation of results for various pieces of equipment,

2. cross-referencing of test results to provide for more uniform application, and

3. application of results to overlay design methodologies. 
Calibration of equipment and instrumentation is partially related to characteristics of specific equipment. However, various aspects of calibration include

A. calibration of the load-application device and B. calibration of instrumentation for response measurements.

Calibration of load-application devices involves an assessment of the frequency and amplitude or displacement for vibratory testers. Oscilloscopes may be used to evaluate those characteristics. A velocity sensor is used with the Kentucky Road Rater to select and(or) check the displacement of the vibrating mass. Calibration of response measurement equipment should include comparisons of measured responses to theoretical inputs induced by some reference loading device, such as a laboratory vibratory shaker operated at known frequencies and amplitudes.

Iniversal application of any evaluation system involves the need for cross-referencing test results for various pieces of equipment so the same conclusions are developed without regard to the system used to collect the field data. Variations in test results may be related to loading conditions, adjustments for temperature and season of testing, and the methodology used in the evaluation of the data. The essential element of any standard method is Elexibility.

Mechanistic approaches to the evaluation of pavement conditions normally involve the calculation of theoretical pavement stresses, strains, and deflections. For example, 
some pavement design and evaluation procedures have been developed within the framework of elastic theory; others have involved visco-elastic theory or finite-element type analyses. Assumptions associated with the use of any "theory" may have a significant impact upon resultant expressions of pavement behavior. Also, the use of "canned" computer programs may be subject to variations relative to the manner in which basic theoretical assumptions are handled within the program. A standard should provide some guidance relative to the usage of various "theories" and computer programs and variations among assumptions therein.

Pavement evaluation procedures also vary relative to the manner in which measured deflection data are processed. Some procedures use only the maximum deflection or the deflection at some specific point on the deflection bowl. Other procedures analyze the shape of the deflection bowl. Generally, evaluations utilizing the complete deflection bowl are considered more reliable since pavement behavior is a function of both the shape and magnitude of the deflection bowl.

Results of pavement evaluation procedures often express pavement behavior in terms of layer moduli of elasticity. While layer moduli are representative of pavement behavior, the use of the moduli may sometimes present problems for some designers. Generally, analyses of moduli and subsequent overlay design require large computer 
capabilities and rather sophisticated data processing. In many situations, this may not be desirable.

An alternate procedure involves an expression of pavement behavior in terms of thicknesses of materials for selected "reference" conditions. Such espressions of pavement behavior are easily adapted to overlay design procedures.

Another aspect of standardization concerns the sampling procedures for specific project requirements. The data must have a sound statistical basis, but at the same time, densities of sampling and testing should not be so excessive as to limit the cost effectiveness of pavement testing and evaluation.

\section{OTHER APPLICATIONS}

The concepts and procedures described in this paper have been applied to dynamic deflection data obtained directly on subgrades, on dense-graded aggregate bases, on pozzolanic bases, on full-depth asphaltic concrete pavements; and on portland cement concrete pavements. The Chevron N-layered program was used to develop for each case theoretical relationships between deflections and various combinations of layer thicknesses, Poisson's ratios, and moduli. The agreement between the theoretical relationships, Road Rater data, and laboratory data has been amazingly good (23).

The Chevron program also has been used to simulate the Road Rater for the analysis of broken and seated portland 
cement concrete pavements prior to and after overlaying. In-place subgrade moduli may be estimated from test data obtained on the intact pavement prior to breaking. Testing after breaking and seating provides estimates of moduli of the broken concrete, using the subgrade modulus obtained prior to breaking. The concepts discussed in this paper are being applied to these situations on an experimental basis. Many questions and relationships still need to be investigated.

Comparisons of sensor deflections from either side of a joint or eraek in a portland-cement conerete pavement may reveal the effectiveness of load transfer from slab to slab. Procedures utlizing Road Rater measurements for these evaluations are still being studied.

It also has been demonstrated that pavement deflections obtained with the Dynaflect can be analyzed utilizing the concepts presented in this paper. It is necessary, however, to develop relationships among deflections, moduli, and layer thicknesses that match the dynamic input of the Dynaflect.

\section{CONCLUSION}

Most approaches to analyzing deflection measurements of pavement systems require a large mainframe computer using iterative procedures to estimate the moduli of the layers. The results present the designer with the task of using those moduli to design overlay thicknesses. The approach presented in this paper greatly simplifies the task for the 
designer. The methodology offered can be processed by (and was, in fact, developed for) a programmable hand-held calculator. A program has been written for a mainframe computer to process deflection data using the methodology described in this paper. The only advantage over processing by hand-held calculators is the significant savings in time to reduce the data.

\section{ACKNOWLEDGEMENTS}

The concepts and procedures reported in this paper have been the subject of extensive research in Kentucky over many years. Much of the effort was supported by the Kentucky Transportation Cabinet (and its predecessors); funding has also been provided by the Federal Highway Administration through HPR programs. The assistance of the Tennessee Department of Transportion also is acknowledged.

The contents of this report reflect the views of the authors who are responsible for the facts and accuracy of the data presented. The paper does not necessarily reflect the official views or policies of the University of Kentucky nor of any of the various supporters of the previous research. This paper does not constitute a standard, specification, or regulation.

\section{REFERENCES}

1. S. P. Timoshenko and J. N. Goodier, Theory of Elasticity, McGraw-Hill, New York, Third Edition, 1972. 
2. J. Michelow, "Analyses of Stress and Displacements in N-Layered Elastic System under a Load Uniformily Distributed on a Circular Area," Chevron Oil Research, Richmond, California, September 24, 1963.

3. J. H. Havens, R. C. Deen, and H. F. Southgate, "Design Guide for Bituminous Concrete Pavement Structures," Transportation Research Program, University of Kentucky, Lexington, August 1981 .

4. H. F. Southgate, R. C. Deen, and J. H. Havens, "Development of a Thickness Design System for Bituminous Gonerete Pavements," Transportation Research Program,

University of Kentucky, Lexington, November 1981.

5. M. W. Witczak, "Asphalt Pavement Performance at Baltimore-Washington International Airport," The Asphalt Institute, College Park, MD, Research Report 74-2, 1974.

6. M. W. Witczak, "A Comparison of Layer Theory Design Approaches to Observed Asphalt Airfield Pavement Performance," Proceedings, The Association of Asphalt Paving Technologists, Phoenix, Arizona, Vol 44, 1975.

7. G. W. Sharpe; H. F. Southgate; and R. C. Deen, "Pavement Evaluation Using Dynamic Deflections," Record 700, Transportation Research Board, Washington, DC, 1979.

8. J. F. Shook and B. F. Kallas, "Factors Influencing Dynamic Modulus of Asphalt Concrete," Proceedings, The Association of Asphalt Paving Technologists, Los Angeles, California, Vol 38, 1969.

9. R. W. Kinchen and W. H. Temple, "Asphaltic Concrete Overlays of Rigid and Flexible Pavements," 
Louisiana Department of Transportation and Development, Baton Rouge, September 1977.

10. K. Majidzadeh, "Dynamic Deflection Study for Pavement Condition Investigation," Ohio Department of Transportation, Columbus, 1974.

11. K. Majidzadeh, "Pavement Condition Evaluation Utilizing Dynamic Deflection Measurements," Ohio Department of Transportation, Columbus, 1977.

12. G. Peterson and L. W. Shepherd, "Deflection Analysis of Flexible Pavements," Utah state Highway Department, Salt Jake City, January 1972.

13. G. Peterson, "Predicting Performance of Pavements by Deflection," Utah State Highway Department, Salt Lake City, May 1975.

14. P. G. Rufford, "A Pavement Analysis and Structural Design Procedure Based on Deflection," Proceedings, Fourth International Conference on the Structural Design of Asphalt Pavements, University of Michigan, Ann Arbor, 1977.

15. H. F. Southgate, G. W. Sharpe, and R. C. Deen, "A Rational System for Design of Thickness of Asphalt Concrete Overlays," Record 700, Transportation Research Board, Washington, DC, 1979.

16. N. K. Vaswani, "Design of Flexible Pavements in Virginia Using AASHO Road Test Results," Record 291, Highway Research Board, Washington, DC, 1970.

17. G. Wiseman, J. Uzan, M. S. Hoffman, I. Ishai, and M. Irivneh, "Simple Elastic Models for Pavement Evaluation Ising Measured Surface Deflections Bowls," Proceedings, 
Fourth International Conference on the Structural Design of Asphalt Pavements, University of Michigan, Ann Arbor, 1977.

18. H. F. Southgate and R. C. Deen, "Temperature Distribution within Asphalt Pavements and Its Relationship to Pavement Deflection," Record 291, Highway Research Board, Washington, DC, 1969.

19. H. F. Southgate and R. C. Deen, "Temperature Distribution within Asphalt Pavements," Record 549, Transportation Research Board, Washington, DC, 1975.

20. H. F. Southgate, R. C. Deen, J. H. Havens, and W. B. Drake, "Kentucky Research: A Flexible Pavement Design and Management System," Proceedings, Fourth International Conference on the Structural Design of Asphalt Pavements, University of Michigan, Ann Arbor, 1977.

21. H. F. Southgate, G. W. Sharpe, R. C. Deen, and J. H. Havens, "Structural Capacity of In-Place Asphaltic Concrete Pavements from Dynamic Deflections," Proceedings, Fifth International Conference on the Structural Design of Asphalt Pavements, The Delft University of Technology, Delft; The Netherlands; 1982.

22. J. A. Deacon and R. C. Deen, "Equivalent Axleloads for Pavement Design," Record 291, Highway Research Board, Washington, DC, 1969.

23. G. W. Sharpe, L. E. Epley, D. L. Allen, H. F. Southgate, and R. C. Deen, "Low-Strength Pozzolanic Materials for Highway Construction," presented to the Fall Meeting of the American Concrete Institute, Kansas City, Missouri, September 1983 (publication pending). 
TABLE 1. PARAMETERS FOR SIMULATION OF ROAD RATER LOADING

\begin{tabular}{|c|c|}
\hline PARAMETER & VALUE \\
\hline Poisson's Ratio & \\
\hline Asphaltic concrete & 0.40 \\
\hline Granular base & 0.40 \\
\hline Subgrade & 0.45 \\
\hline Contact Pressure (MPa) & \\
\hline Low $(3.24-\mathrm{kN})$ load & 0.183 \\
\hline High $(4.19-\mathrm{kN})$ load & 0.231 \\
\hline Layer Thicknesses ( $\mathrm{mm}$ ) & \\
\hline Asphaltic concrete & $\begin{array}{l}51 \text { thru } 355 \\
\text { (four increments) }\end{array}$ \\
\hline Granular base & $\begin{array}{l}51 \text { thru } 659 \\
\text { (four increments) }\end{array}$ \\
\hline $\begin{array}{l}\text { Full-depth asphaltic } \\
\text { concrete }\end{array}$ & $\begin{array}{l}102 \text { thru } 510 \\
\text { (eight increments) }\end{array}$ \\
\hline $\begin{array}{c}\text { Modulus of Elasticity } \\
\text { Asphaltic concrete }\end{array}$ & $\begin{array}{l}\text { a) } \\
\text { l. } 38 \text { thru } 13.80\end{array}$ \\
\hline Subgrade & $\begin{array}{l}\text { (nine increments) } \\
0.041 \text { thru } 0.41 \\
\text { (nine increments) }\end{array}$ \\
\hline $\begin{array}{l}1 \mathrm{MPa}=145 \mathrm{ibf} / \mathrm{sq} \text { in. } \\
1 \mathrm{kN}=225 \mathrm{lbf} \\
1 \mathrm{~mm}=0.04 \mathrm{in} .\end{array}$ & \\
\hline
\end{tabular}


TABLE 2. COMPARISON OF RESULTS OF ANALYSIS PROCEDURES WHEN DATA IS MISSING

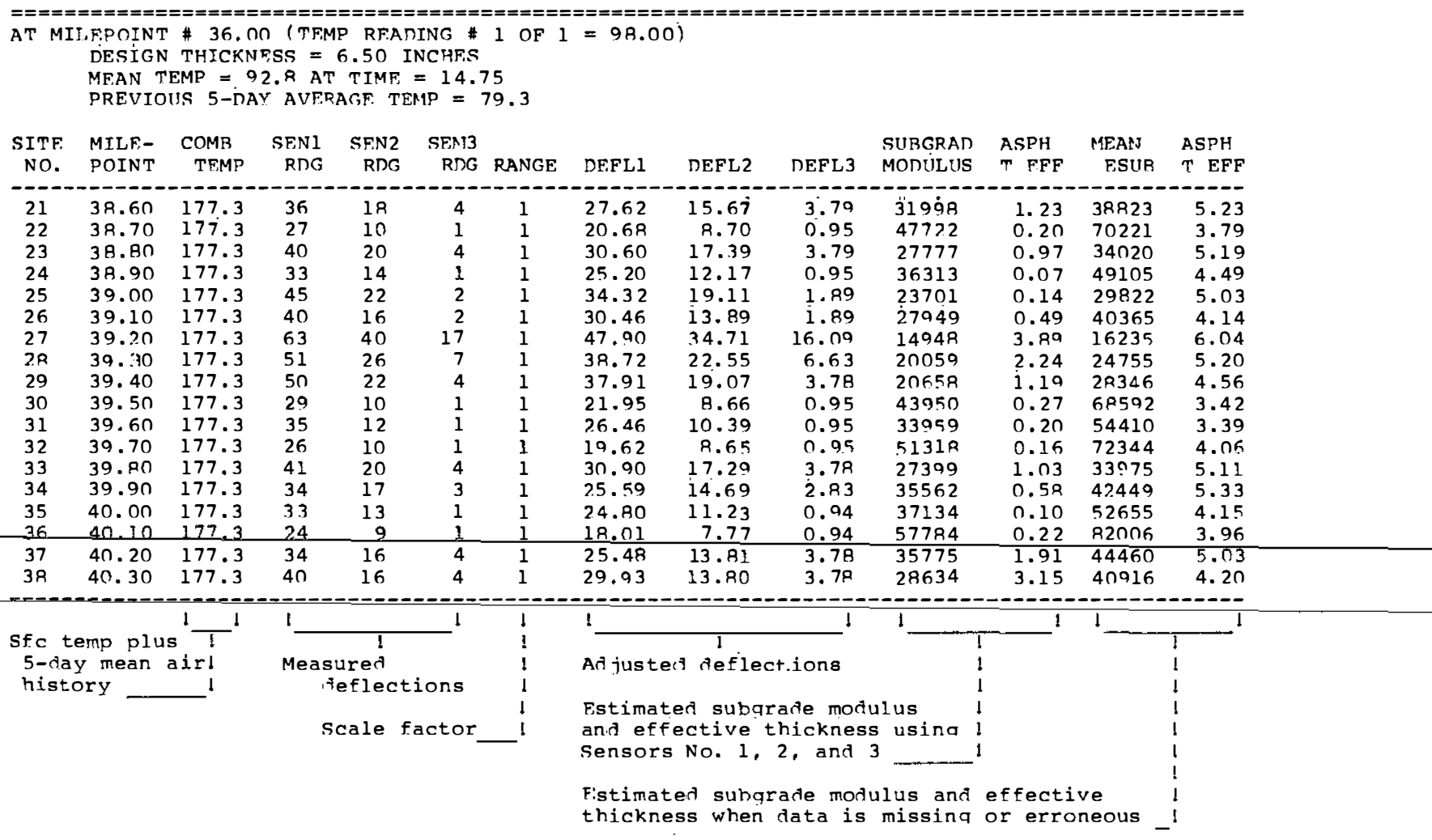


TABLE 3. EQUATION AND CONSTANTS FOR DEFLECTION ADJUSTMENT FACTORS FOR THE KENTUCKY ROAD RATER

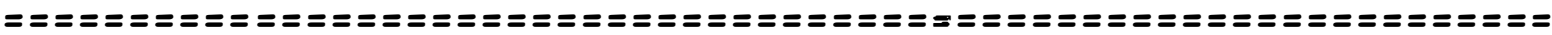

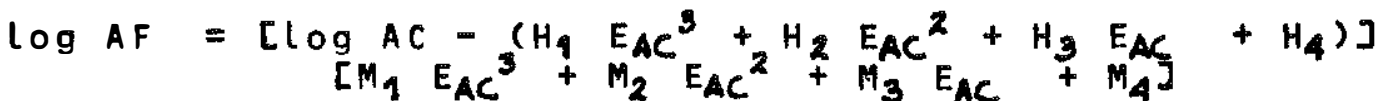

in which $A F=$ deflection adjustment factor,

$A C=$ thickness of asphaltic concrete (inches),

$E_{A C}=$ mean modulus of elasticity of asphaltic concrete (psi), and

$j \quad=$ Road Rater sensor number $(1,2,3)$.

THREE LAYERED PAVEMENTS

Crushed-stone Base less than 8 inches thick

$\begin{array}{rrrrrr}j & H_{1} & H_{2} & H_{3} & H_{4} \\ 1 & -2.0312535 E-19 & 7.1127654 E-13 & -8.4587 n 20 E-n 7 & 0.25466949 \\ 2 & 7.2614981 E-20 & -1.0302809 E-13 & -1.3874220 E-n 7 & 0.46 n 69097 \\ 3 & 1.6419243 E-19 & -3.3570986 \mathrm{E}-13 & -4.2060526 E-n 8 & 0.46081522\end{array}$

${ }_{1}^{j} \begin{array}{cccc}M_{1} & M_{2} & M_{3} & M_{4} \\ 1-n 225763 E-10 & -4-4990262 E-13 & 7.0628626 E-07 & -0.37155742\end{array}$

$24.3336498 E-20 \quad-2.2 n 91077 E-13 \quad 4.5988841 E-n 7 \quad-0.30474423$

$3 \quad 3.3403716 E-20-1.6395133 E-13 \quad 3.4805071 E-07-n .23820381$

Crushed-stone Base equal to or greater than 8 inches thick

\begin{tabular}{|c|c|c|c|}
\hline $\begin{array}{c}H_{1} \\
-2.3472762 E-2 n \\
8.6274124 E-20 \\
1.1280263 E-19\end{array}$ & $\begin{array}{r}H_{2} \\
1.1931522 E-13 \\
-1.3810588 E-13 \\
1.7456748 E-13\end{array}$ & $\begin{array}{c}H_{3} \\
-2.9552194 E-07 \\
-8.8295169 E-08 \\
-1.3783142 E-07\end{array}$ & $\begin{array}{c}\mathrm{H}_{4} \\
0.15345469 \\
0.42052283 \\
0.6 n 022647\end{array}$ \\
\hline $\begin{array}{c}M_{9} \\
8.611 n \pi 78 E-20 \\
3.5850121 E-20 \\
2.1116466 E-20\end{array}$ & $\begin{array}{c}M_{2} \\
-3.8725065 E-13 \\
-1.8167083 E-13 \\
-1.0783377 E-13\end{array}$ & $\begin{array}{c}M \mathrm{~B} \\
6.2848481 \mathrm{E}-07 \\
3.8532939 \mathrm{E}-07 \\
2.5034102 \mathrm{E}-07\end{array}$ & $\begin{array}{c}M_{4} \\
-0.34173343 \\
-0.25976352 \\
-0.18049747\end{array}$ \\
\hline
\end{tabular}

TWO LAYERED PAVEMENTS

\begin{tabular}{|c|c|c|c|}
\hline $\begin{array}{c}H \\
-1.1966613 E-18 \\
8.4194518 E-20 \\
2.8337843 E-19\end{array}$ & $\begin{array}{c}H_{2} \\
3.64199 \cap 0 E-12 \\
-1 . \cap 8 \cap 33 \cap 9 E-13 \\
-6.0413664 E-13\end{array}$ & $\begin{array}{c}H 3 \\
-3.3712189 E-06 \\
-2.9750845 E-07 \\
6.2056443 E-08\end{array}$ & $\begin{array}{c}\mathrm{H}_{4} \\
0.40220812 \\
0.63921054 \\
0.84294820\end{array}$ \\
\hline $\begin{array}{c}M_{1} \\
1.0486807 E-19 \\
1.0429773 E-19 \\
9.6133265 E-2 n\end{array}$ & $\begin{array}{c}M_{2} \\
-4.5399608 E-13 \\
-4.7586726 E-13 \\
-3.9709184 E-13\end{array}$ & $\begin{array}{c}M_{3} \\
6.6726565 E-07 \\
7.9423 \cap n 8 E-n 7 \\
6.8153597 E-n 7\end{array}$ & $\begin{array}{c}M 4 \\
-0.32106577 \\
-0.44438965 \\
-0.41509883\end{array}$ \\
\hline
\end{tabular}


TABLE 4. EQUATIONS AND COEFFICIENTS FOR ROAD RATER DEFLECTIONS

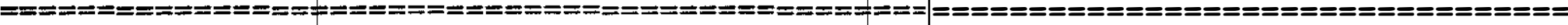

loq $\Delta=\mathrm{K}$ log $\mathrm{E}_{\mathrm{S}}+\mathrm{L}$

$\mathrm{K}=\mathrm{N}_{1} A C^{3}+\mathrm{N}_{2} A C^{2}+\mathrm{N}_{3} \mathrm{AC}+\mathrm{N}_{4}$

$\mathrm{L}=\mathrm{N}_{5} A C^{3}+\mathrm{N}_{6} A C^{2}+\mathrm{N}_{7} \mathrm{AC}+\mathrm{N}_{8}$

$\mathrm{N}_{i}=\mathrm{A}_{i} \mathrm{DGA}^{4}+\mathrm{B}_{i} \mathrm{DGA}^{3}+\mathrm{C}_{i} \mathrm{DGA}^{2}+\mathrm{D}_{i} \mathrm{DGA}+\mathrm{F}_{i}$

in which $A C=$ thickness of asphaltic concrete ( $i$ nches),

$\mathrm{DGA}=$ thickness of crusheri-stone base (inches),

$\mathrm{E}_{\mathbf{S}}=$ modulus of elasticity of the subqrade (psi), and

$\Delta=$ deflection.

A

NO. 1 SENSOR

$1-8.0276712 \mathrm{E}-09$ 2. $2880623 \mathrm{E}-07$

$-2.0069119 \mathrm{E}-06$

$5.3511621 \mathrm{E}-06$

$3.8112800 F,-O R$

$-1.0927940 \mathrm{E}-06$

$9.6888879 \mathrm{E}-06$

8 $-2.6361517 \mathrm{E}-05$

NO. 2 SENSOR

$1-1.9422702 \mathrm{E}-08$ $5.2579366 \mathrm{E}-07$ $-4.2869807 \mathrm{E}-06$ 9.8983780F,-OK $6.1453952 \mathrm{E}-0 \mathrm{R}$ $-1.9486070 \mathrm{E}-06$ 1. $5831303 \mathrm{E}-05$ $-3.6284025 E-05$

$4.4637935 \mathrm{E}-07$ $-1.2956090 \mathrm{~F}, 05$ 0.00011636 $-0.00032005$ $-2.1142292 \mathrm{~F}, 06$ $6.1604764 \mathrm{E}-05$ $-0.00055752$

0.00155888

$1.0770627 \mathrm{E}-06$ $-2.9137271 F,-05$ 0.00023786 $-0.00055346$ $-3.3927169 E-06$ 0.00010728 $-0.00087303$ 0.00202136

NO. 3 SENSOR

$1 \quad 2.1333448 \mathrm{E}-08$ $-6.1003392 E-07$ $5.4277510 \mathrm{E}-06$ $-1.5081292 \mathrm{E}-05$ $-1.0456648 E-07$ $2.9858350 E-06$ $-2.6465435 \mathrm{E}-05$ 7.2699360E-05
$-1.2598323 \mathrm{E}-06$ 3.6138955F,-05 $-0.00032212$ 0.00089525

6.1644249F:-06 $-0.00017641$

0.00156508 $-0.00429505$
$-7.8334349 \mathrm{E}-\mathrm{r}(16$ 0.00023158 $-0.00213561$ 0.00617403 $3.6712 .485 \mathrm{~F}-1.15$ $-0.00108653$ 0.01004067 $-0.02921499$

$-1.8518686 F-1 / 5$

0.00049930

$-0.00407118$ 0.00958628 $5.7851557 \mathrm{E}-115$ $-0.00180868$ 0.01469200 $-0.03448633$

$2.4207689 \mathrm{E}-05$ $-0.00069872$

0.00626602 $-0.01749993$

$-0.00011799$

0.00339148

$-0.03021266$ 0.08308389
$4.3700774 \mathrm{~F}-05$

$-0.00126428$

0.01152101

$-0.03601869$

$-0.00019713$

0.00564980

$-0.05039463$

0.14909581

$9.5507480 \mathrm{E}-05$ $-0.00251336$

0.01974778

$-0.04540810$

$-0.00028477$

0.00847179

$-0.06471592$

0.13878339

$-0.00016422$

0.00483808

$-0.04474861$

0.13007837

0.00078800

$-0.02303053$

0.21073267

$-0.60401394$
$\mathrm{E}$

0.00015920

$-0.00603433$

0.07053069

$-0.94738380$

$-0.00079876$

0.03181695

$-0.42286904$

6.27491080

$8.9416760 \mathrm{E}-05$ $-0.00416610$

0.07009015

$-1.12011456$

$-0.00038341$

0.01804679

$-0.34277031$

6.61774653

$4.6358157 \mathrm{E}-05$ $-0.00319426$

0.07028740

$-1.27529337$

$-0.00010359$

0.01019562

$-0.28067328$

6.84595514 
TABLE 5. EFFECTIVE THICKNESSES OF ASPHALTIC CONCRETE BEFORE AND AFTER MILLING

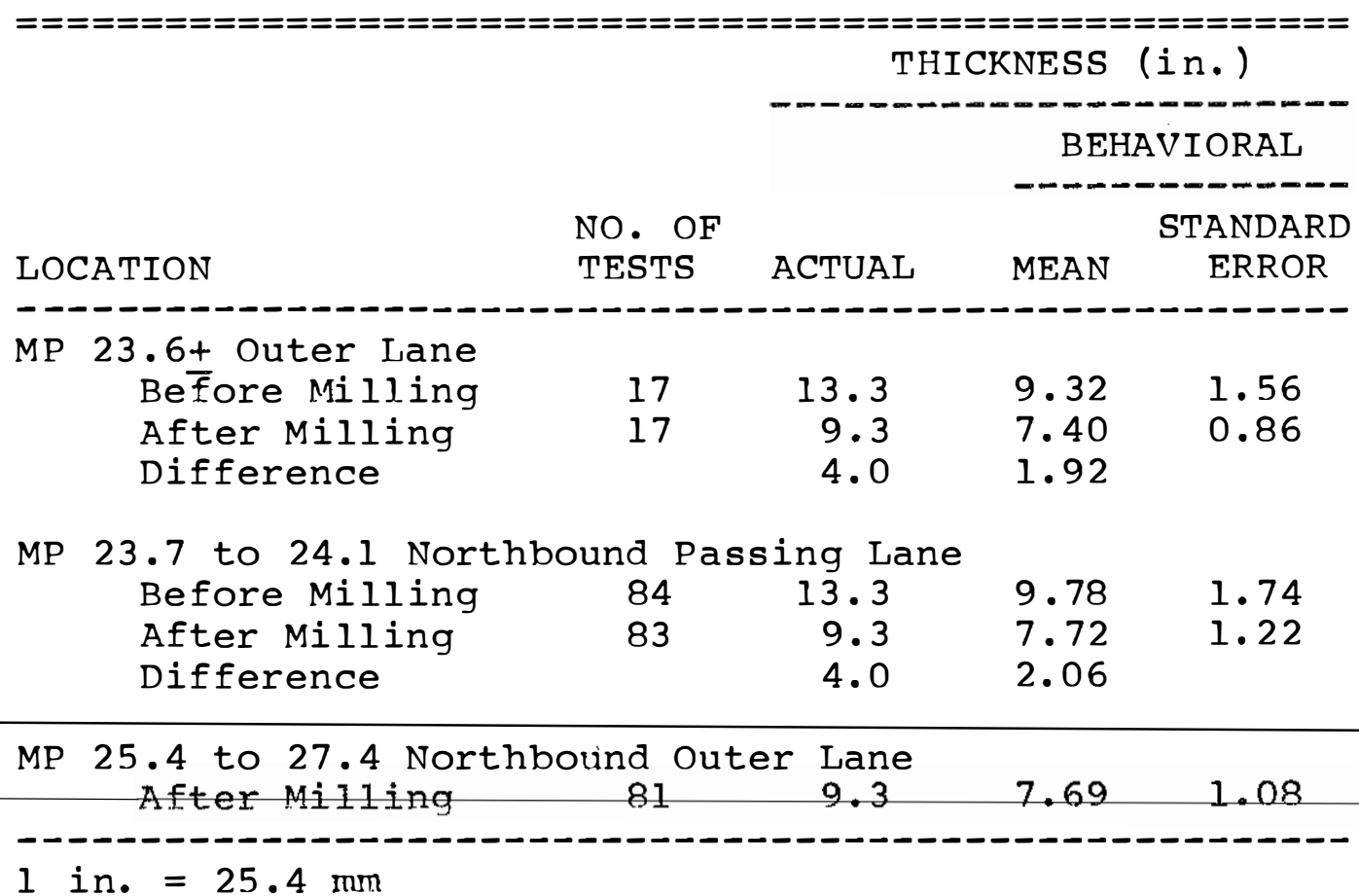


TABLE 6, COMPARISON OP RESULTS OF ANAL̈YSES FOR KY 114, MAGOFFIN COUNTY, KENTUCKY

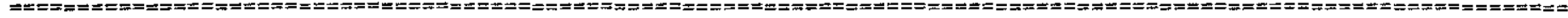
AT MILF:POINT \#0.00

DFSIGN TIIICKNESS $=6.00$ INCHF.S

MF.AN TPMP $=95.1$ AT TIME $=14.02$

PRFVIOUS 5-DAY AVERAGF TEMP $=96.5$

SITF MILE- COMB SFN1 SFN2 SFN3

\begin{tabular}{cccc} 
NO. & POINT & TFMP \\
\hline 1 & $0.0 n$ & 191.6 & 41.6 \\
2 & 0.10 & 191.6 & 28 \\
3 & 0.20 & 191.6 & 40 \\
4 & 0.30 & 191.6 & 40 \\
5 & 0.40 & 191.6 & 41 \\
6 & 0.50 & 191.6 & 36 \\
7 & 0.60 & 191.6 & 43 \\
8 & 0.70 & 191.6 & 44 \\
9 & 0.80 & 191.6 & 49 \\
10 & 0.90 & 191.6 & 59 \\
11 & 1.00 & 191.6 & 36 \\
12 & 1.10 & 191.6 & 58 \\
13 & 1.20 & 191.6 & 64 \\
14 & 1.30 & 191.6 & 67 \\
15 & 1.40 & 191.6 & 43 \\
\hline
\end{tabular}

Sfc temp plus !
5-ray mean air!
history
Scale factor

\begin{tabular}{ll}
41 & 27 \\
28 & 17 \\
40 & 26 \\
40 & 23 \\
41 & 25 \\
36 & 20 \\
43 & 23 \\
44 & 25 \\
49 & 29 \\
59 & 41 \\
36 & 23 \\
58 & 36 \\
64 & 36 \\
67 & 40 \\
43 & 21 \\
\hline
\end{tabular}

RANGE

SURGRAD

31.98
NFFL2 DFFL3 MODULUS

ASPH SPR

$\begin{array}{rrr}23.80 & 11.48 & 27260 \\ 14.98 & 5.74 & 45983\end{array}$

$\begin{array}{llll}31.14 & 22.90 & 7.6 .5 & 28271\end{array}$

$31.11 \quad 20.25$

7.6 .5

28308

ค. $60 \quad 27404$

$6.69 \quad 37.781$

27.94217 .50

$33.35 \quad 20.23$

34.09

$7.64 \quad 25744$

8.60 24980

$14.33 \quad 21589$

1589
16769

21.97
7.64
11.46996

$45.62 \quad 36.03$

$27.81 \quad 20.20$

$\begin{array}{llll}44.76 & 31.61 & 11.46 & 17210\end{array}$

$\begin{array}{llll}49.35 & 31.60 & 13.37 & 15062\end{array}$

$\begin{array}{llll}51.61 & 35.10 & 15.27 & 14165\end{array}$

$4.77 \quad 26012$

TT IVSPR

1

1.49

$\begin{array}{lllll}3.64 & 12.2 & 1.4 & 8.9 & 3.41\end{array}$

12.2

3.

R. $9 \quad 3.41 \quad-0.2$

$\begin{array}{lllllr}1.35 & 12.6 & 2.2 & 8.9 & 3.41 & 1.2\end{array}$

$2.78 \quad 12.2$

2.5

1.5

2.6014 .6

$3.06 \quad 11.5$

3.3411 .2

$3.16 \quad 9.6$

5.707 .5

5.0214 .7

1.967 .7

$\begin{array}{rrrrrr}1.96 & 7.7 & 4.2 & 8.9 & 3.41 & -0.9 \\ 2.14 & 6.7 & 2.9 & 8.9 & 3.41 & 0.5 \\ 3.86 & 6.3 & 3.3 & 8.9 & 3.41 & -0.1\end{array}$

1.497 .4

$3 \cdot 3-8.9-3.41-0.1$

$\begin{array}{llll}3.7 & 8.9 & 3.41 & -0.3\end{array}$

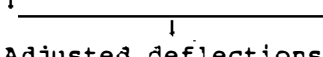
1

$\begin{array}{lll}8.9 & 3.41 & -0.7\end{array}$

Adjuster deflections

Estimater suhạracie morulus and effective thickness using

sensors No. 1, 2, and 3

Sprinatime CRR and nverlay thickness for each test point

Minimum design hasea on analyses of strip charts 1

1
$-0.7$ 


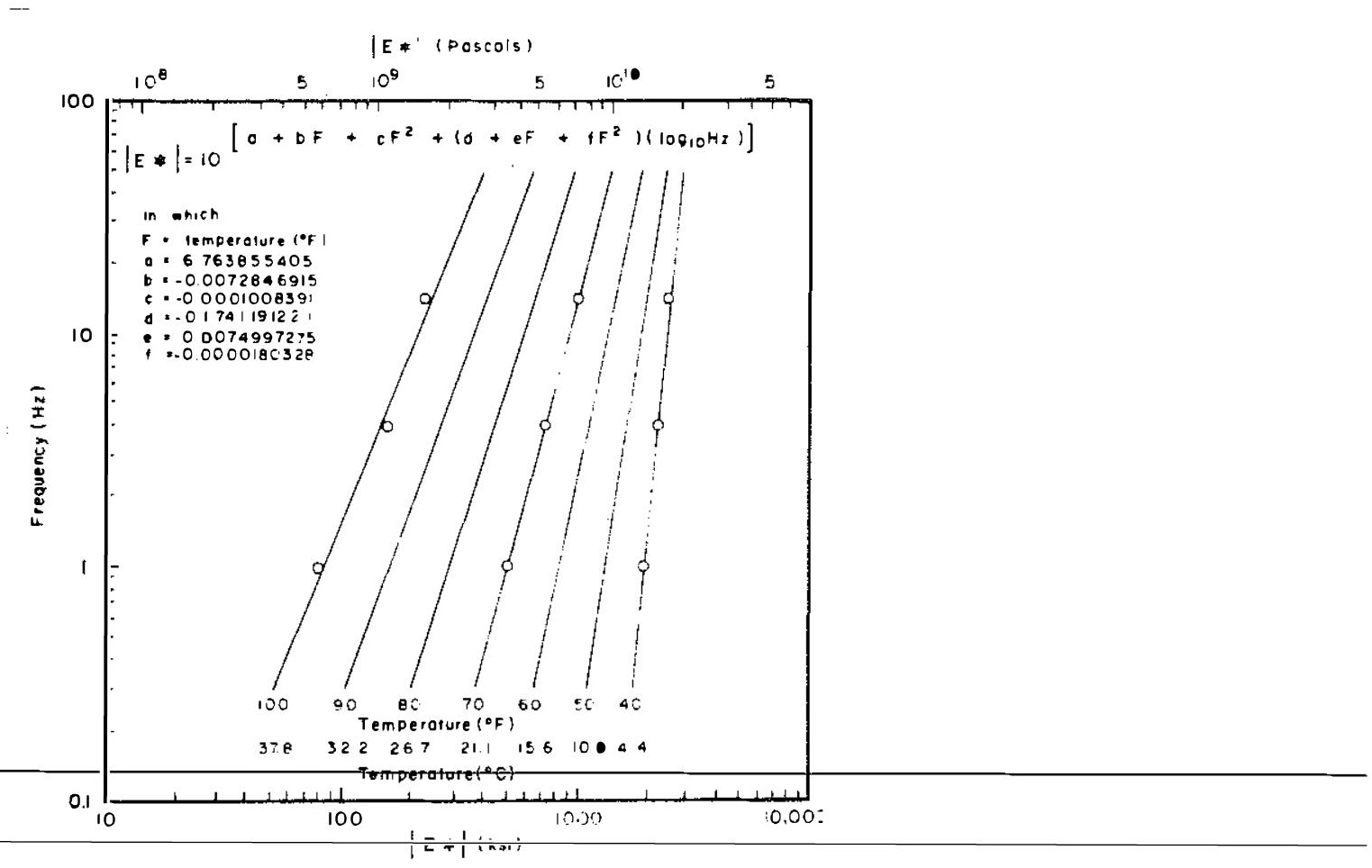

Figure 1. Relationships amoni Temperature of Pavemert, Frequency of Loading, and Modulus of Elasticity of the Asphaltic Concrete.

Distance From Point of Looding

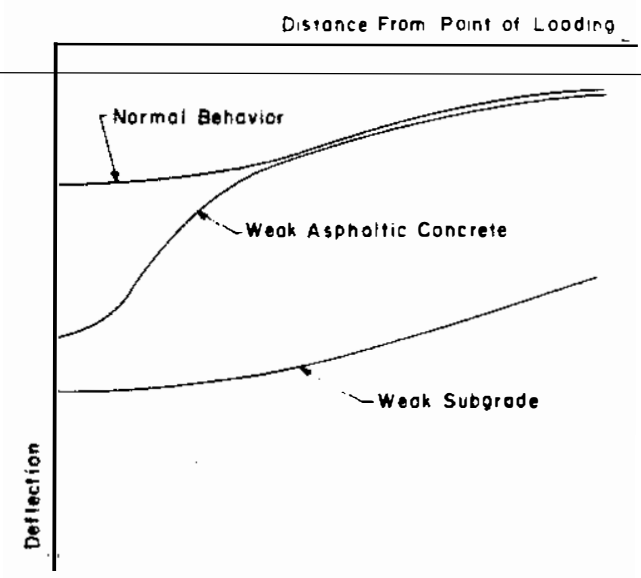

Figure 2. Sketches of Typical Deflection Bow Js. 


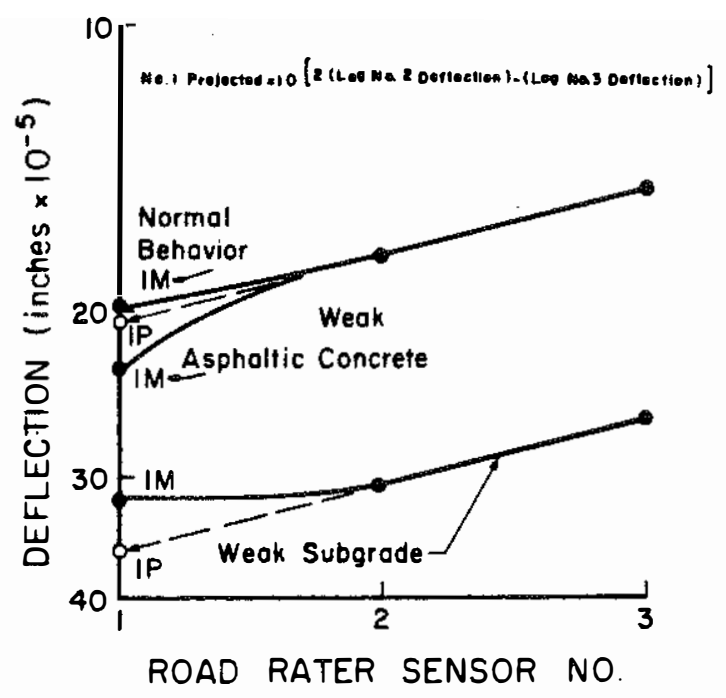

Figure 3. Surface Deflection as a Function of Nistance from the Road Rater Load Hear, Illustratins the netermination of the No. 1 Projected Deflection ( 1 P)

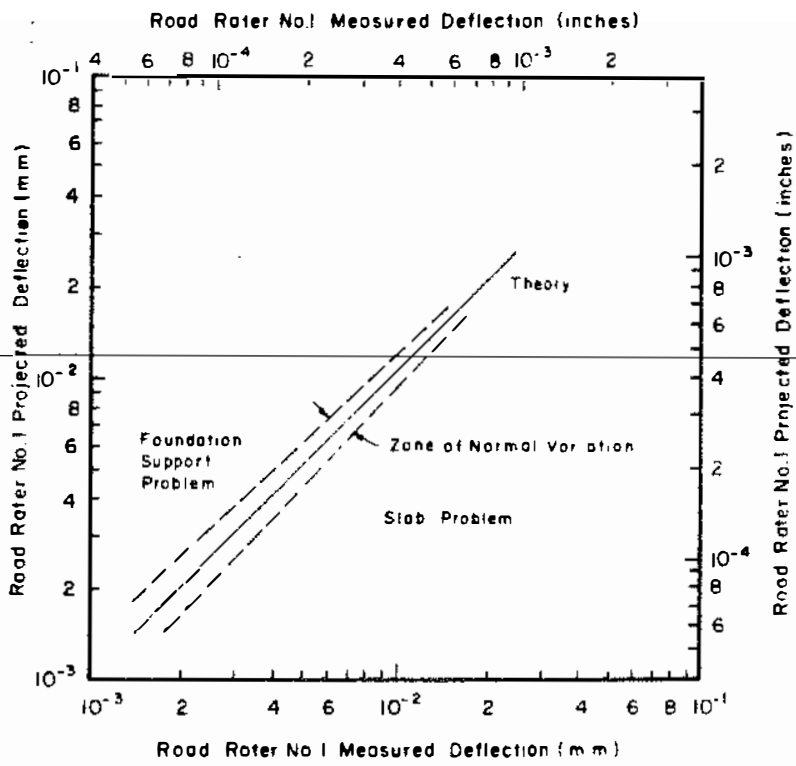

Figure 4. Relationship between Road Rater No. 1 Projected Deflection and Road Rater No. 1 Sensor Deflection (Measured). 


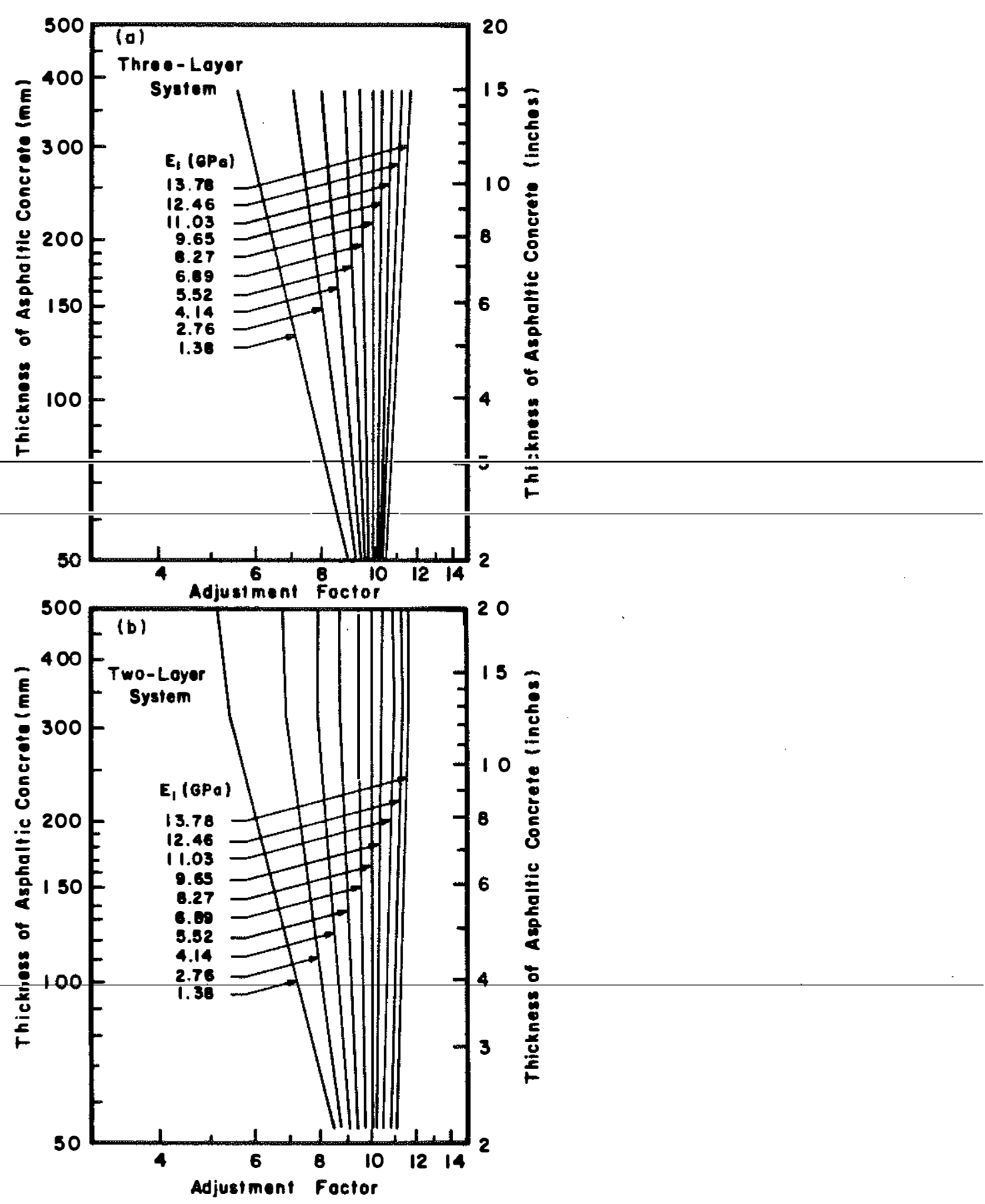

Figure 5. Relationship (for Sensor No. 1) between Thickness of Asphaltic Concrete and Temperature Adjustment Factor for (a) Three-layered Pvements and (b) - Two-layered Pavements. 


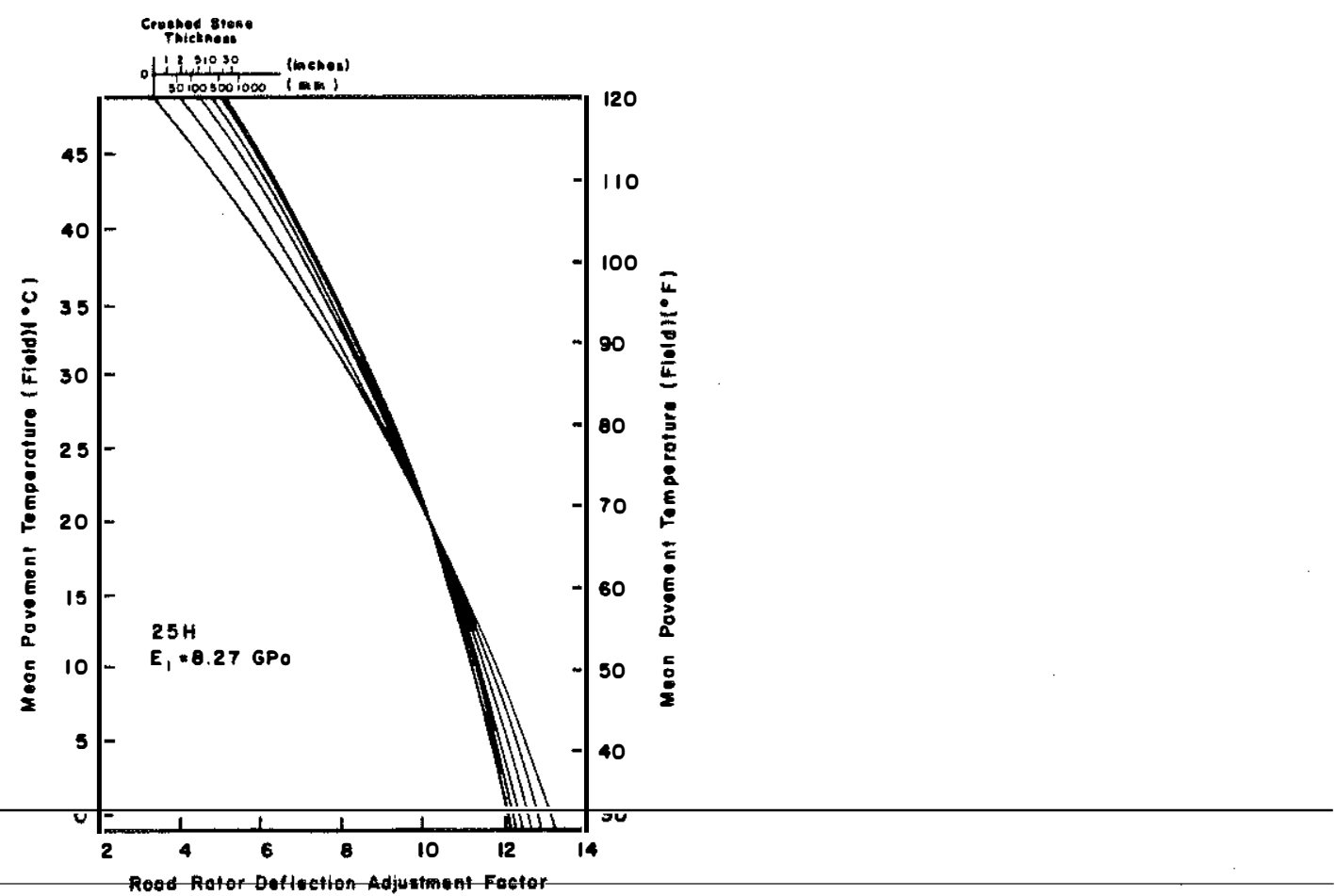

Figure 6. Relationship (for Sensor No. 1) between Mean Pavement Temperature and Road Rater Deflection Adjustment Factor at $21 \mathrm{C}$ and $25 \mathrm{~Hz}$.

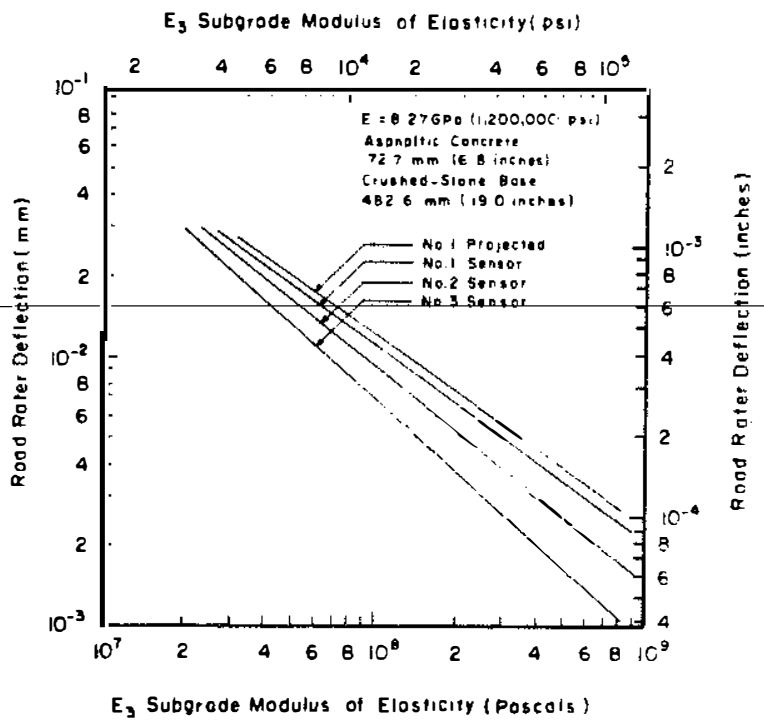

Figure 7. Theoretical Relationships hetween Road Rater Deflection and Subqrade Modulus of Elasticity for a Given Pavement Structure and Asphaltic Concrete Modulus. 


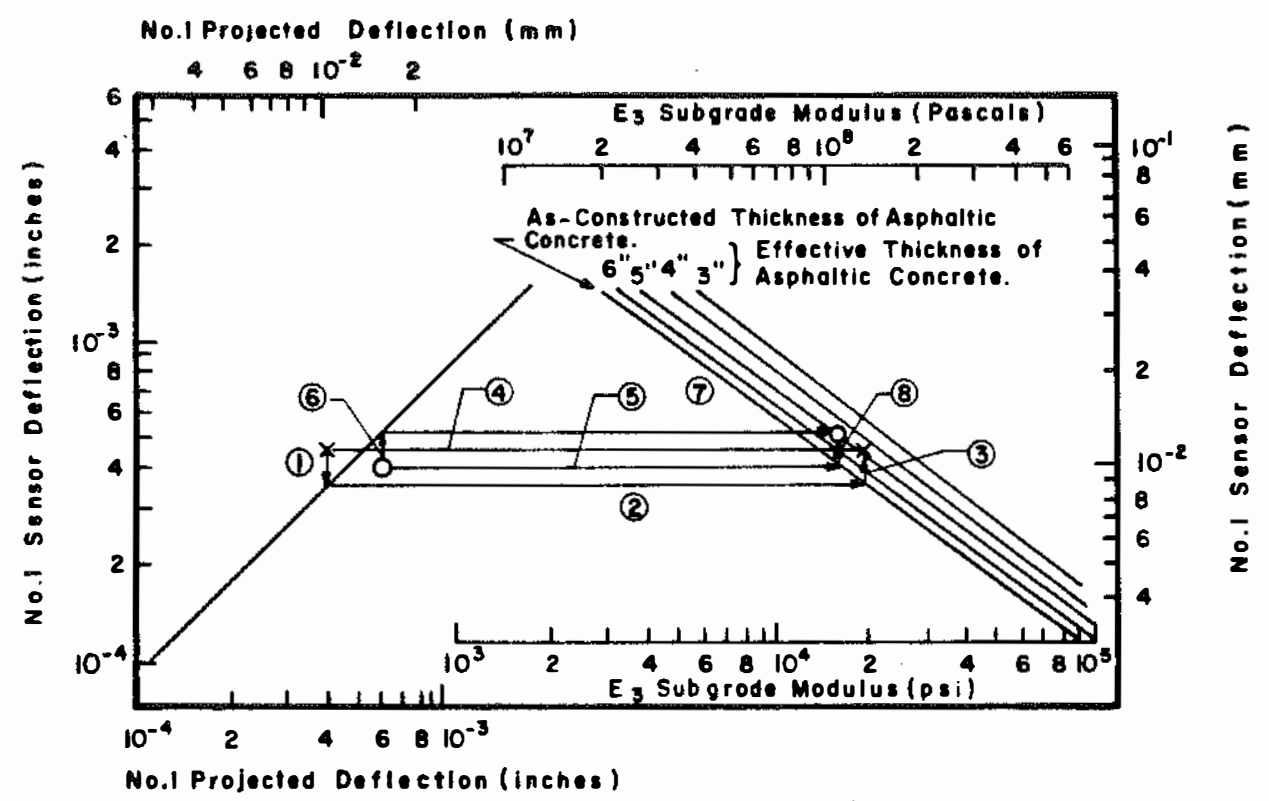

Figure ?. Illustration of a Method for Estimating In-place Suharade Moriulus and Effective Thickness of Asphaltic Concrete.

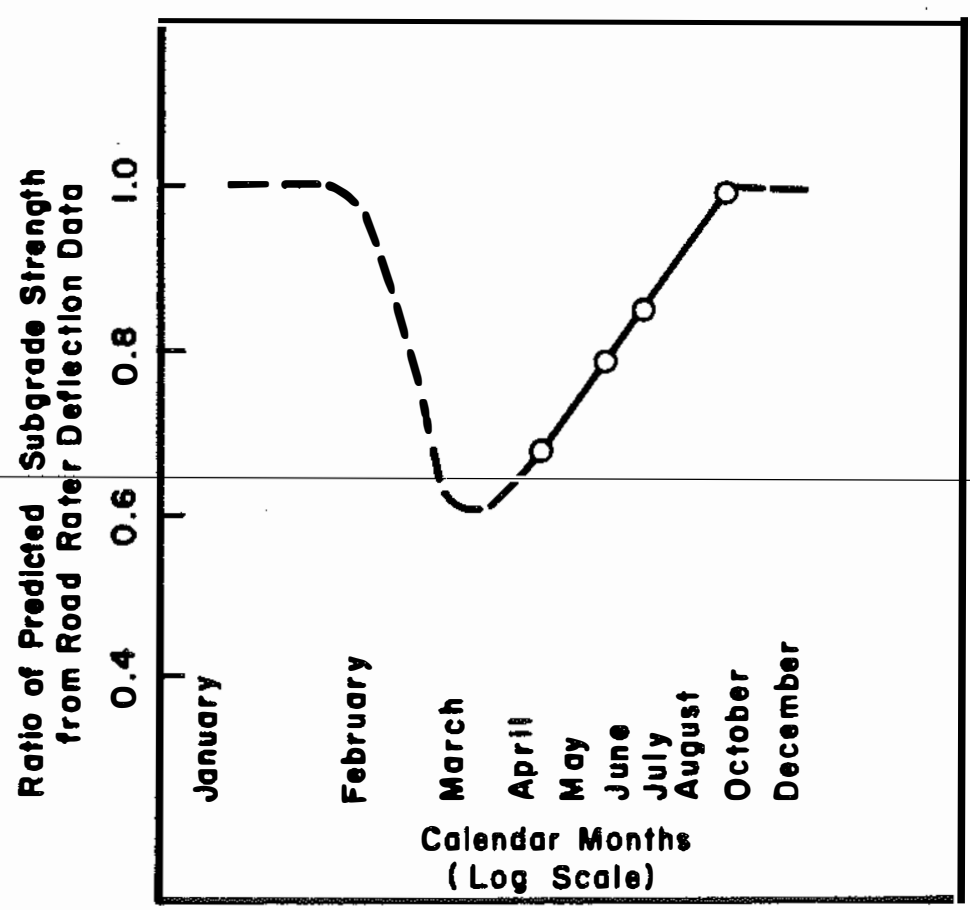

Figure 9. Subgrade Modulus as a Function of Time of Year. 


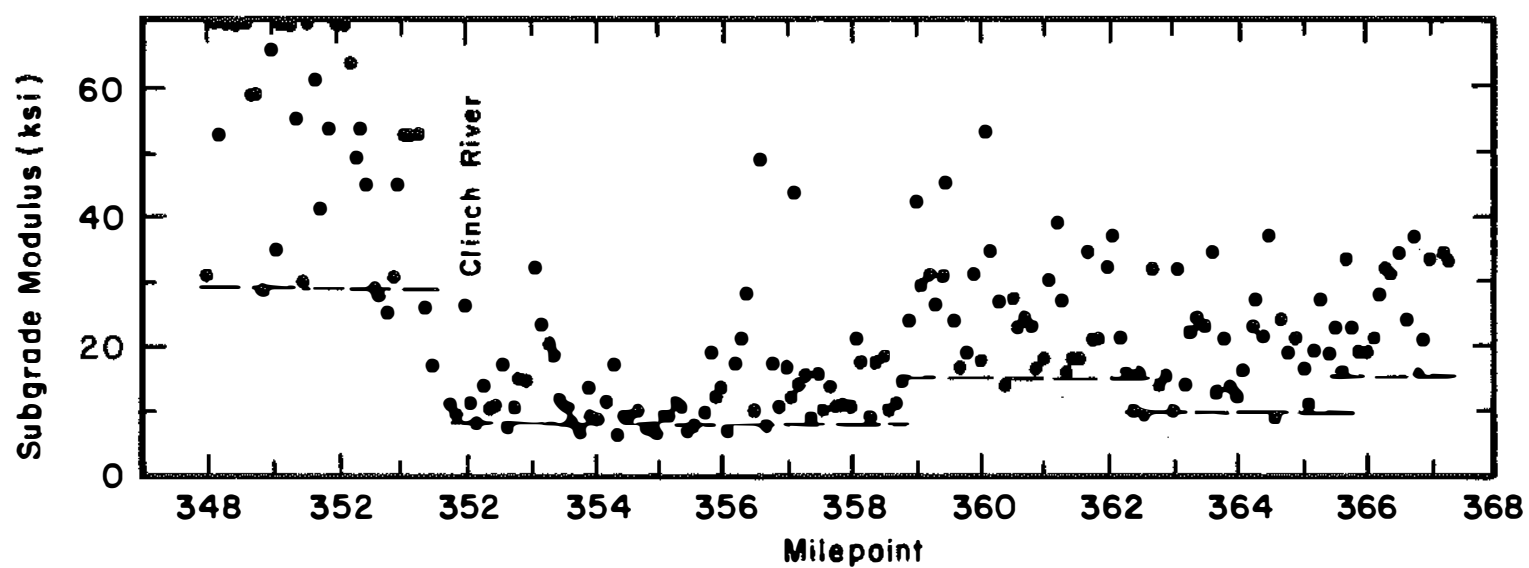

Figure 10. Strip Chart of Subgrade-Morulus.

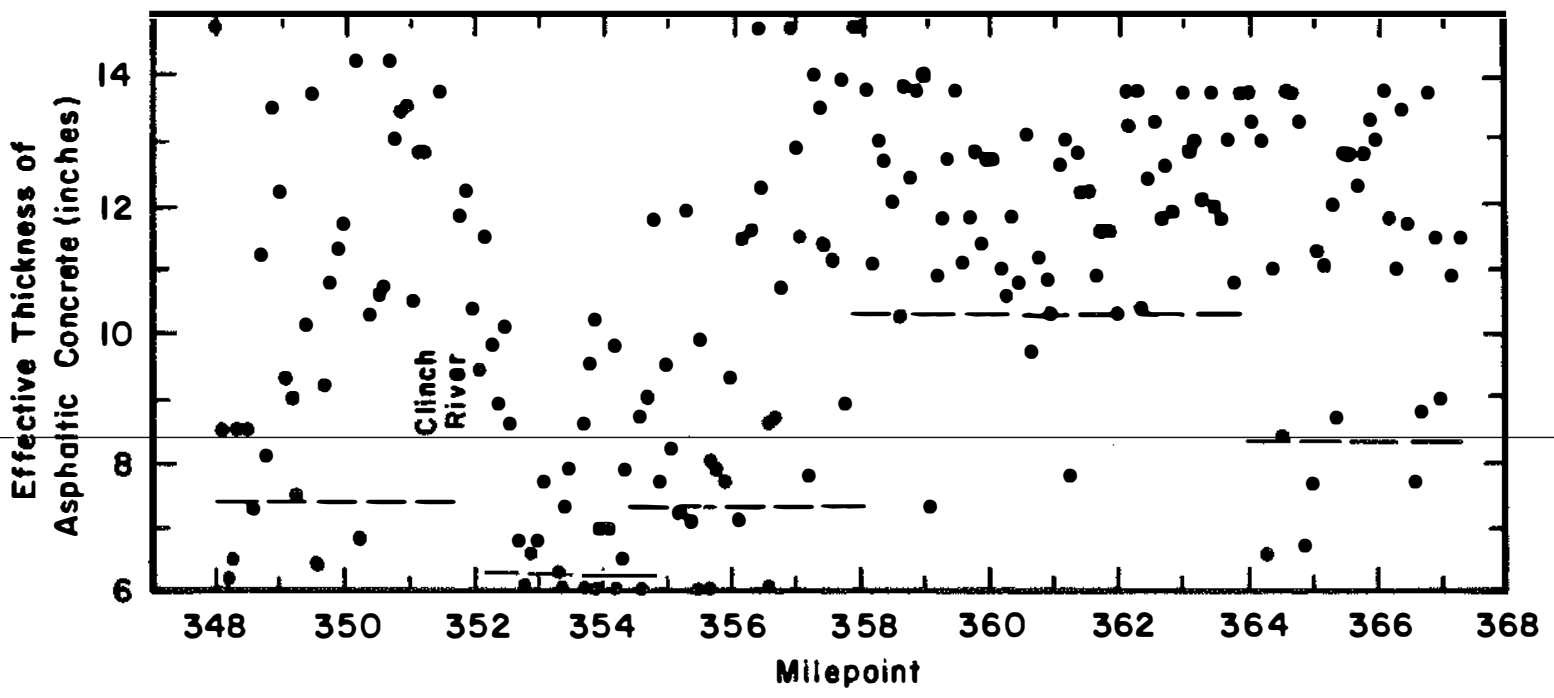

Figure 11. Strip Chart of Effective Thickness of Asphaltic Concrete. 


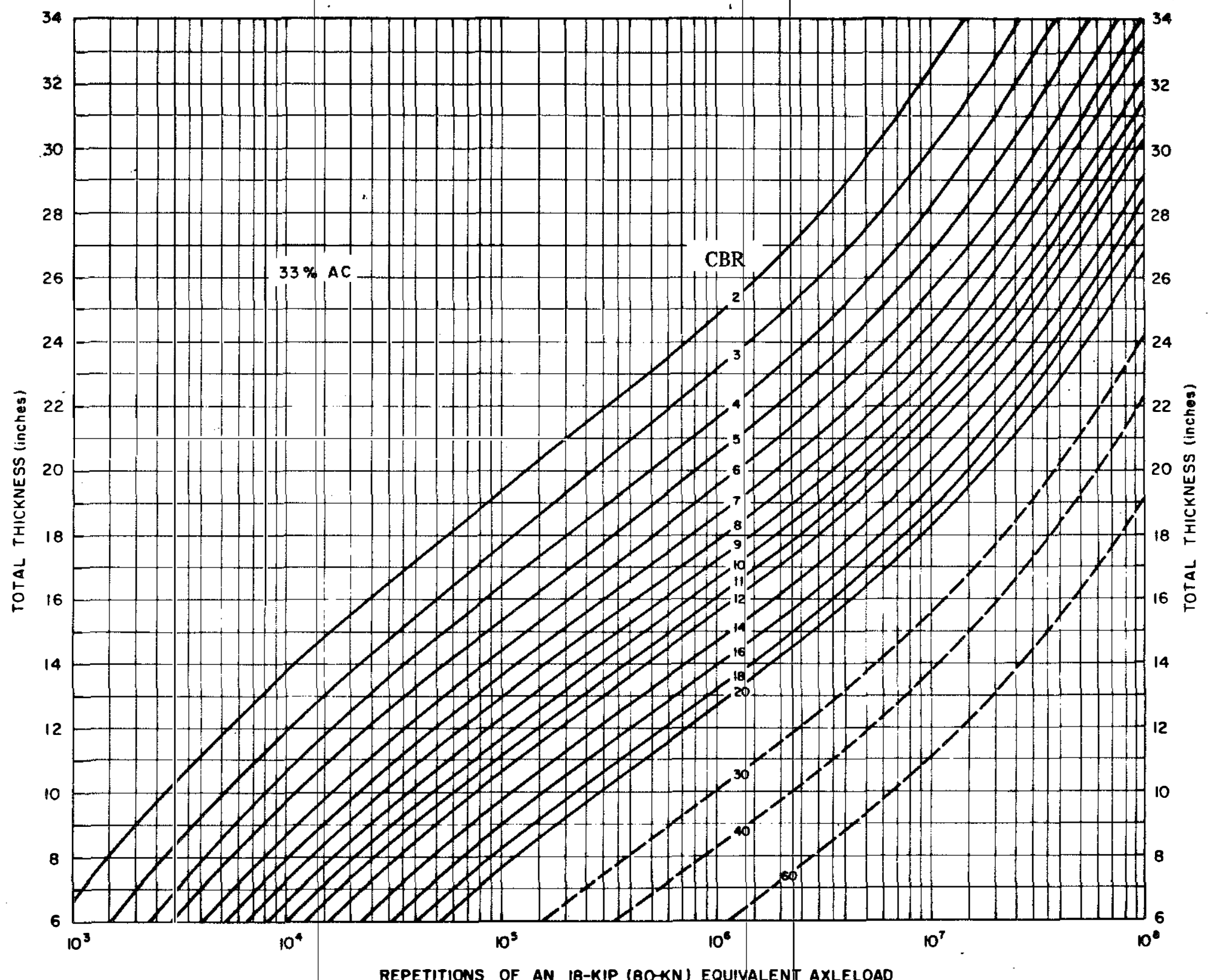

Figure 12. Simnlified Design Curves for Thickness of:"

Asphaltic Concrete Iayer (a) 33 Percent, (h) 50

Percent, and (c) 75 Percent of the Total

Pavement Thickness. 


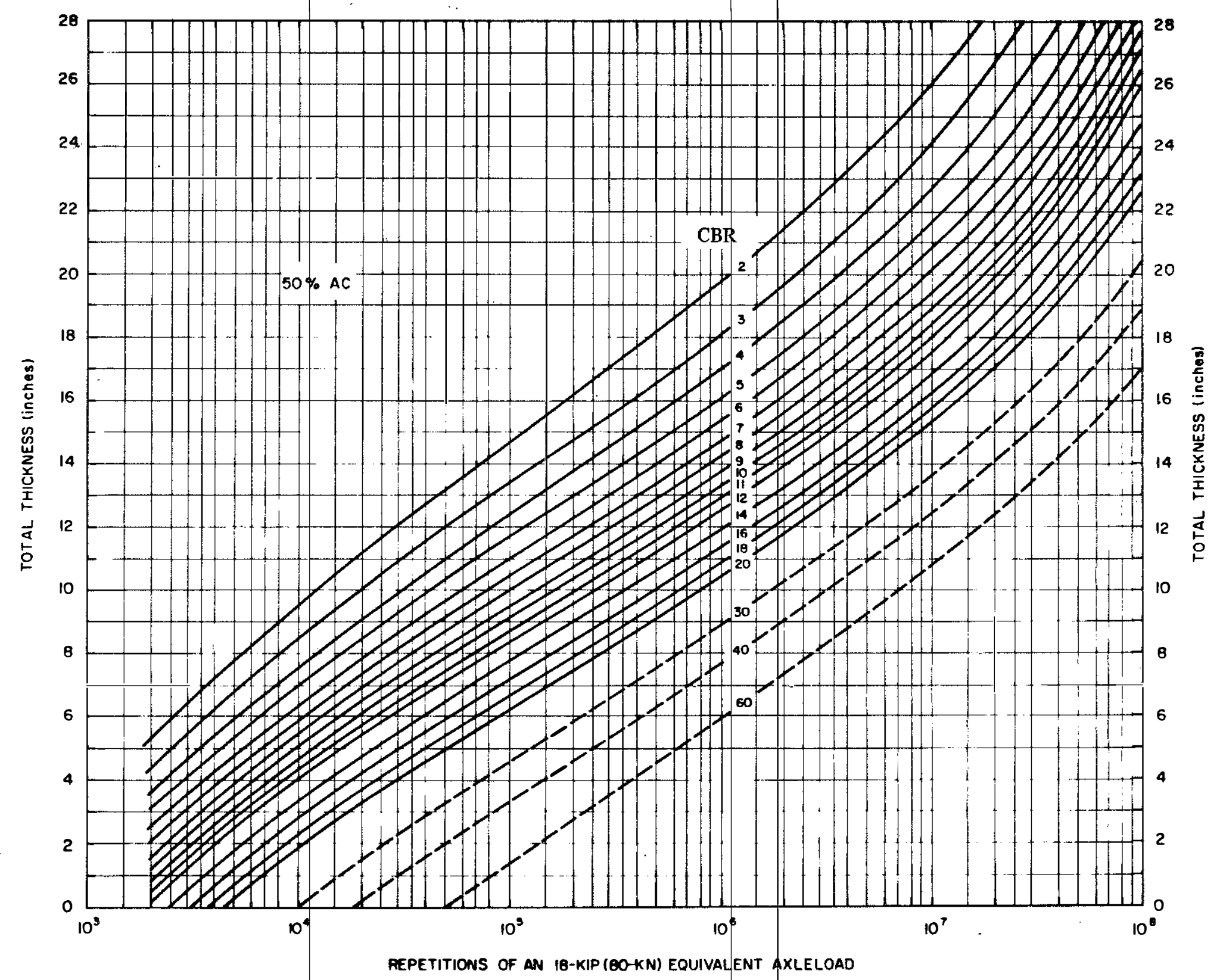

Figure 12. (Continued) 


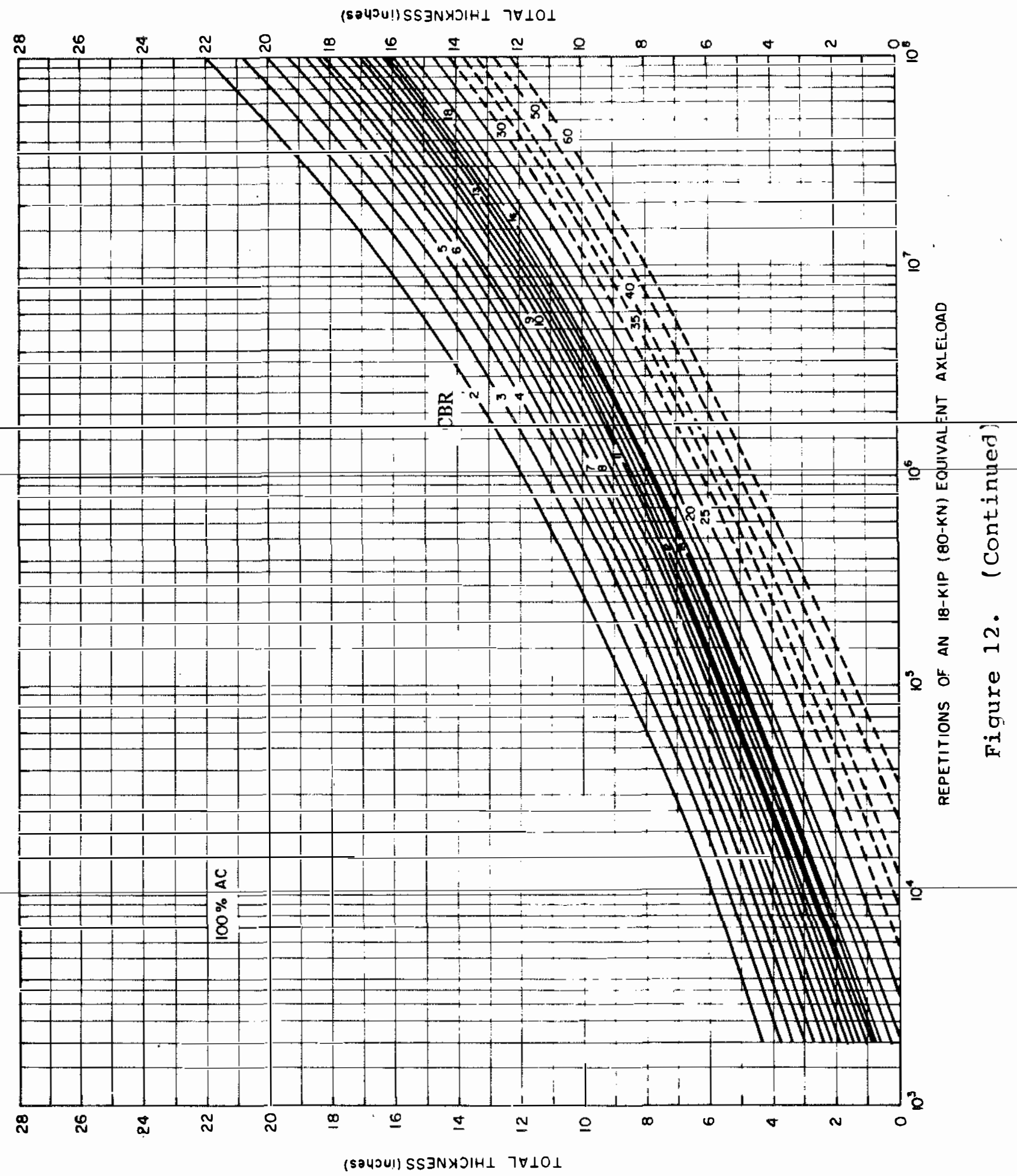




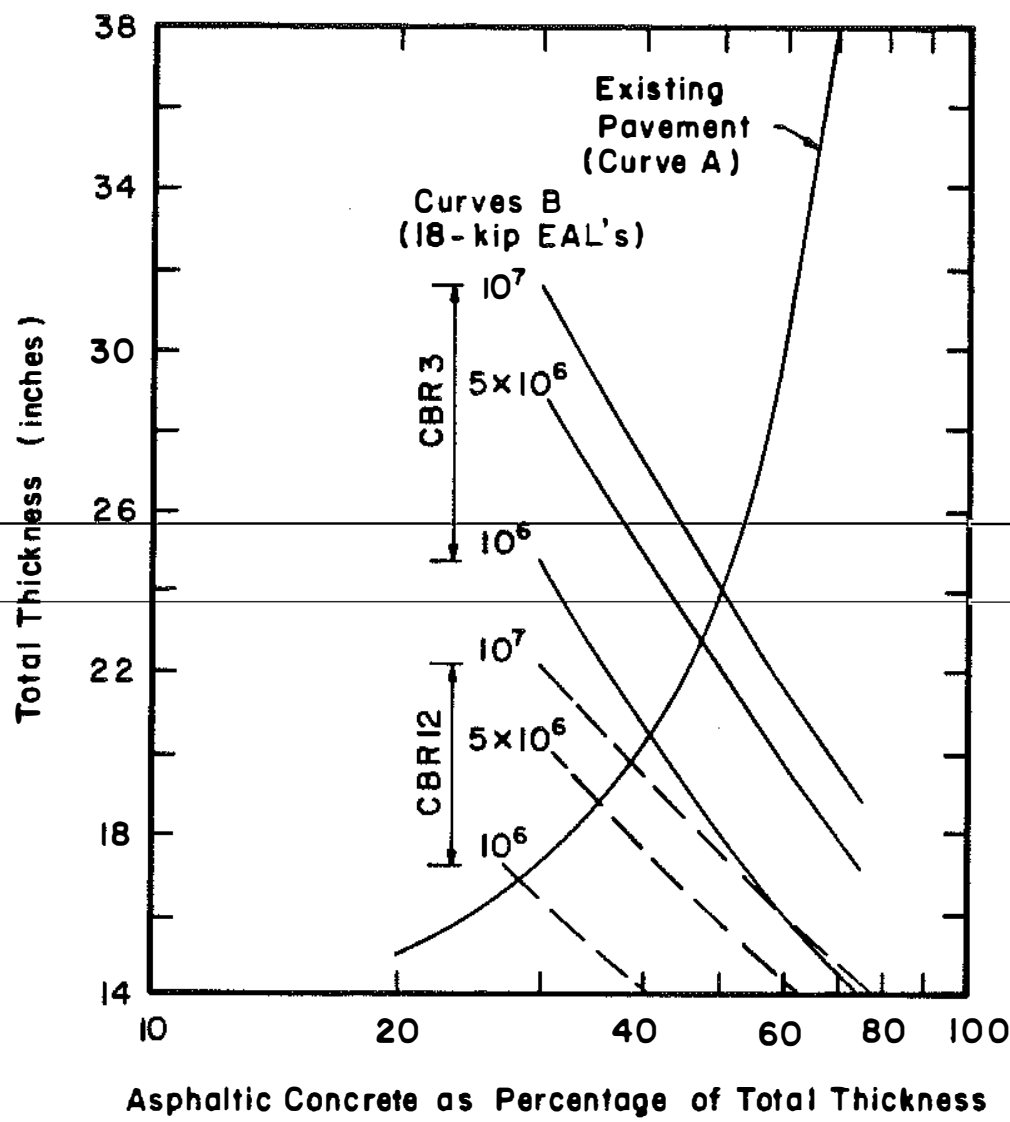

Figure 13. Example of Relationship between Tntal Desion Thickness and Percentage of Total Thickness due to Asphaltic Concrete. 


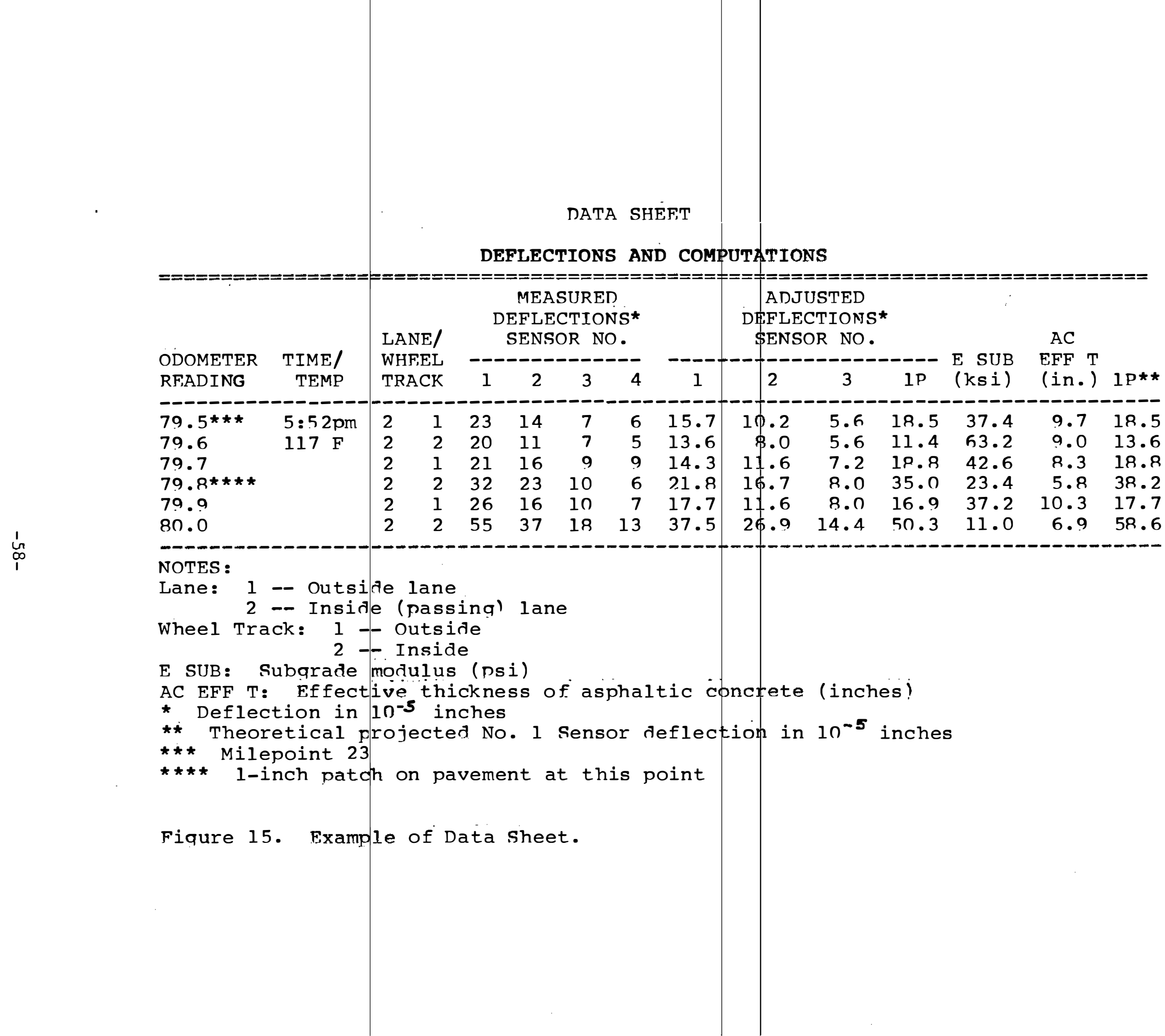




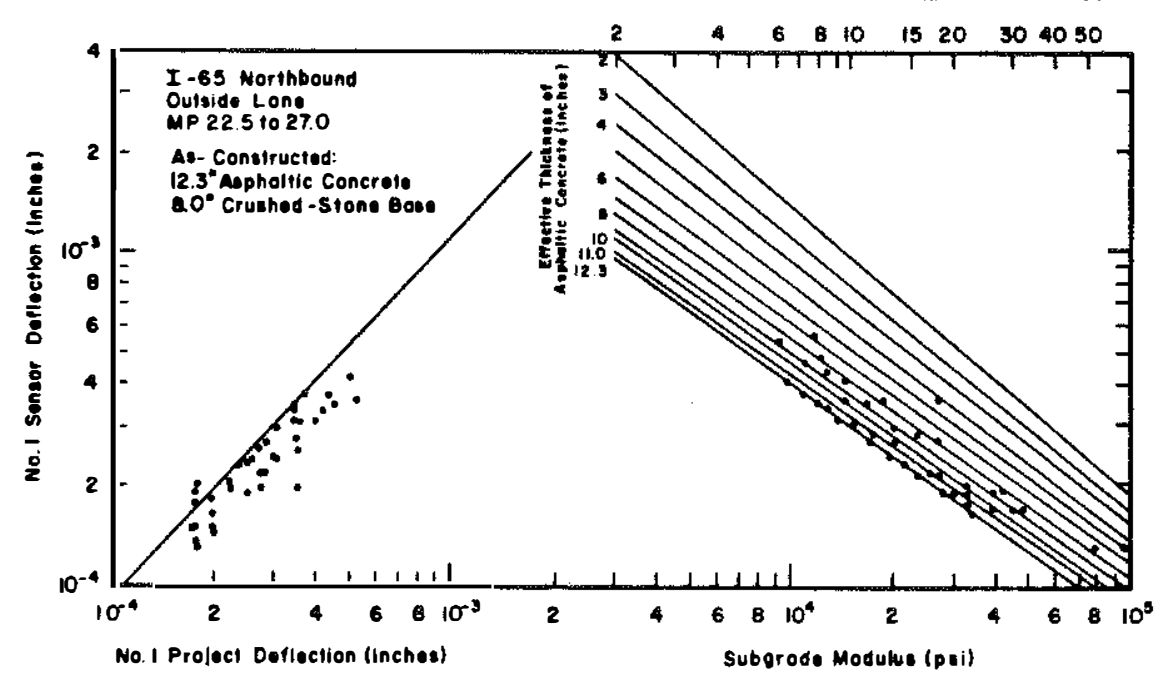

Figure 16. Graphical netermination of Suharade Modulus and Fffective Thickners of Asphaltic Concrete.

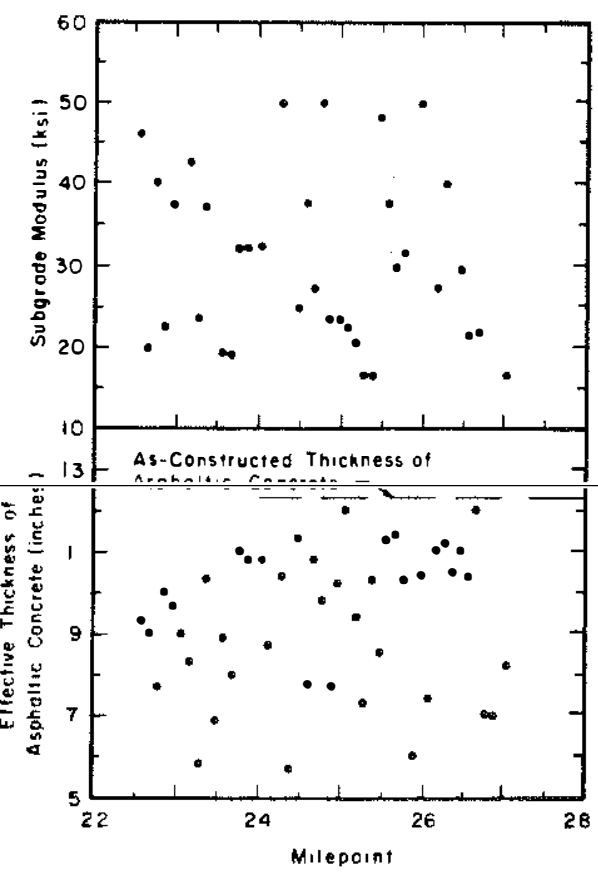

Figure 17. Strip Maps to Determine Design Parameter. 


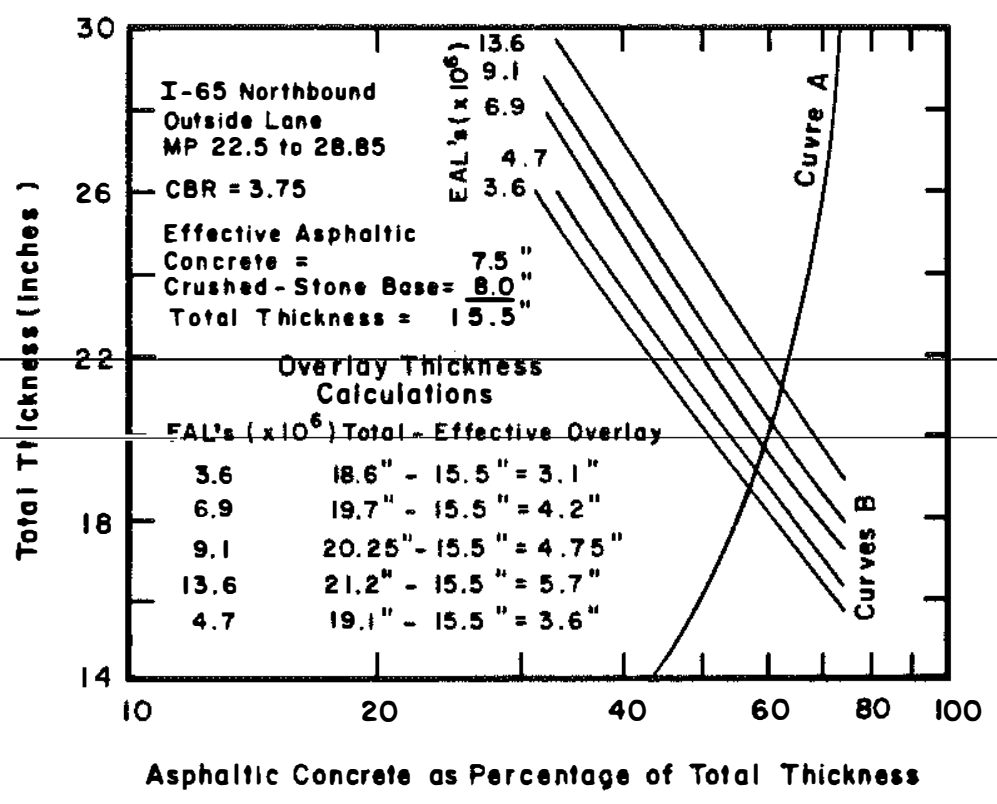

Figure 18. Determination of overlay Thickness. 
DATA SHEET

SUMMARY OF OVERLAY THICKNESS DESIGNS

Date: 8-4-82 Section: 4 MP 22.6 to MP 27.2

Projection Description: I65, MAROWALL GOUNYY TENNESGEE

Nonmbouno Meoran (TNoire) Lane

Section Description: MP 22.5 to MP 26.85

Direction: Noater

CBR: Mean:

14.8

$1.2816 \times$ Standard Error:

8.66

Design CBR (difference):

6.14

Spring CBR:

$(\underline{0.6} \times$ Design $C B R)$

3. 7

Behavior Thickness of Existing Asphaltic Concrete:

Mean (inches):

9.83

1.2816 $\times$ Standard Error (inches):

2.81

Design EAL (millions): $3.6 \quad 4.7 \quad 6.9 \quad 9.1 \quad 13.6$

Total Design

Thickness (inches): $18.6 \quad 19.1 \quad 19.7 \quad 20.3 \quad 21.2$

Asphaltic Concrete

Thickness (inches): 10.6 11.1 11,7 12,

Effective Thickness

(Mean less $1.28 / 6 \mathrm{x}$

Standard Error)

(inches):

$7.5 \quad 7.5 \quad 7.5 \quad 7.5 \quad 7.5$

Overlay Thickness

(Kentucky) (inches): $3.1 \quad 3.6 \quad 42 \quad 4.8 \quad 5.7$

Overlay Thickness

(AASHTO) (inches)

$(1.1 \times \mathrm{KY}$ Overlay): $\quad 3.4 \quad 4.0 \quad 4.6 \quad 5.3 \quad 6.3$

Figure 19. Summary of Overlay Thickness Designs. 